\title{
Psychosocial well-being and supportive care needs of cancer patients and survivors living in rural or regional areas: a systematic review from 2010 to 2021
}

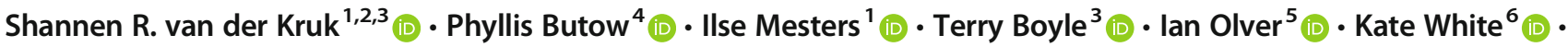 \\ Sabe Sabesan ${ }^{7}$ (D) Rob Zielinski ${ }^{8,9}$ (D) Bryan A. Chan ${ }^{10}$ (D) Kristiaan Spronk $^{2,11}$ (I) $\cdot$ Peter Grimison ${ }^{12}$ (iD) \\ Craig Underhill ${ }^{13}$ (D) - Laura Kirsten ${ }^{14}$. Kate M. Gunn ${ }^{2,11}$ (D) on behalf of the Clinical Oncological Society of Australia
}

Received: 3 March 2021 / Accepted: 13 July 2021 / Published online: 14 August 2021

(C) The Author(s), under exclusive licence to Springer-Verlag GmbH Germany, part of Springer Nature 2021

\begin{abstract}
Purpose To summarise what is currently known about the psychosocial morbidity, experiences, and needs of people with cancer and their informal caregivers, who live in rural or regional areas of developed countries.

Methods Eligible studies dating from August 2010 until May 2021 were identified through several online databases, including MEDLINE, EMBASE, PsychINFO, and RURAL (Rural and Remote Health Database). Results were reported according to the PRISMA guidelines and the protocol was registered on PROSPERO (CRD42020171764).

Results Sixty-five studies were included in this review, including 20 qualitative studies, 41 quantitative studies, and 4 mixed methods studies. Qualitative research demonstrated that many unique psychosocial needs of rural people remain unmet, particularly relating to finances, travel, and accessing care. However, most (9/19) quantitative studies that compared rural and urban groups reported no significant differences in psychosocial needs, morbidity, or quality of life (QOL). Five quantitative studies reported poorer psychosocial outcomes (social and emotional functioning) in urban cancer survivors, while three highlighted poorer outcomes (physical functioning, role functioning, and self-reported mental health outcomes) in the rural group.

Conclusion Recent research shows that rural people affected by cancer have unique unmet psychosocial needs relating to rurality. However, there was little evidence that rural cancer survivors report greater unmet needs than their urban counterparts. This contrasts to the findings from a 2011 systematic review that found rural survivors consistently reported worse psychosocial outcomes. More population-based research is needed to establish whether uniquely rural unmet needs are due to general or cancer-specific factors.
\end{abstract}

Keywords Cancer $\cdot$ Rural $\cdot$ Psychosocial $\cdot$ Healthcare needs $\cdot$ Informal caregivers $\cdot$ Oncology

Kate M. Gunn

kate.gunn@unisa.edu.au

Shannen R. van der Kruk

Shannen.vanderKruk@unisa.edu.au

Phyllis Butow

phyllis.butow@sydney.edu.au

Ilse Mesters

ilse.mesters@maastrichtuniversity.nl

Terry Boyle

Terry.Boyle@unisa.edu.au

Ian Olver

ian.olver@adelaide.edu.au

Kate White

kate.white@ sydney.edu.au

Sabe Sabesan

Sabe.Sabesan@health.qld.gov.au
Rob Zielinski

Rob.Zielinski@health.nsw.gov.au

Bryan A. Chan

Bryan.Chan@health.qld.gov.au

Kristiaan Spronk

sprkj003@mymail.unisa.ed

Peter Grimison

peter.grimison@1h.org.au

Craig Underhill

Craig.Underhill@bordermedonc.com.au

Laura Kirsten

laura.kirsten@health.nsw.gov.au

Extended author information available on the last page of the article 


\section{Introduction}

Understanding the psychosocial well-being and supportive care needs of people with cancer has become an important public health concern [1]. As the number of people diagnosed with cancer and survival rates improve [2], more people living with cancer will require ongoing cancer treatment, surveillance, and supportive care to address their psychosocial needs $[3,4]$. Supportive care can be defined as care that helps a person with cancer and their family cope with cancer and its treatment, from pre-diagnosis through the process of diagnosis and treatment to cure, continuing illness or death and into bereavement [5]. Unfortunately, given the increasing prevalence of cancer survivors and limited health workforce, current survivorship care leaves survivors with significant unmet needs [6-8]. Previous research indicates survivors living in rural or regional areas are likely to have more unmet needs than those residing in urban areas $[9,10]$. Fortunately, targeted research is being undertaken to understand the specific, culturally complex indigenous cancer issues [11], as outcomes are even worse for these members of the rural population. However, it is also important to develop understanding about the supportive care needs of the significant number of nonindigenous rural people affected by cancer and caregivers, to improve service delivery models, and to inform new approaches.

Research suggests that rurality negatively impacts survival. A survival analysis in Australian cancer patients showed that cancer patients living in remote areas are $35 \%$ more likely to die within 5 years of a cancer diagnosis than those living in urban areas $[12,13]$. Similar patterns have been found in various geographical regions around the world and using multiple definitions of rurality [14]. Contributing factors may include more labour-intensive work schedules, delayed diagnosis, geographic isolation, and lower levels of income, education, and socioeconomic status (SES) $[12,15,16]$. As there are fewer cancer services in rural or regional areas, rural people with cancer may also experience a lack of local support and services, and often have to travel significant distances or relocate to access cancer care [17-20]. This may affect their treatment decisions and follow-up care post-treatment, and profoundly impact their psychosocial well-being, resulting in poorer health status [20-22].

In 2011, a systematic review on psychosocial well-being and the supportive care needs of people living in urban and rural/regional areas, diagnosed with cancer, was published online [23]. Bringing together the literature on psychosocial morbidity in rural areas (excluding studies on medical outcomes, survival, interventions etc.), this influential 2011 review included 37 studies and found that the majority of controlled studies reported worse psychosocial outcomes for rural cancer patients, who had higher needs, particularly in the domains of daily living and physical functioning, compared to urban cancer patients. Furthermore, many rural patients and families reported rural-specific challenges including travel, financial, emotional, and relationship challenges. The review concluded that more research was needed that included people with heterogenous cancers from rural and urban settings to confirm these disparities. Since then, increasing research interest in this field has been driven, at least in part, by the finding that although cancer survival is improving overall, disparities between rural and urban populations are continuing to grow [24]. Addressing rural cancer disparities has become a key priority area for the National Cancer Institute in the United States (US), which has led to an increase in the amount of research funding being directed towards this field [25]. However, the impact of rurality on psychosocial morbidity remains less clear than the impact that it has on physical morbidity and survival. Therefore, the purpose of this study was to systematically review studies on levels of psychosocial morbidity and the experiences and needs of people with cancer and their informal caregivers, living in rural or regional areas, that have been published in the last 10 years, since the 2011 review. Where studies included data on both psychosocial and physical morbidity, we report only the former.

\section{Methods}

This systematic literature review was conducted in accordance with the Preferred Reporting Items for Systematic Reviews and Meta-Analyses (PRISMA) [26]. The study protocol was registered in the online database of PROSPERO (CRD42020171764).

\section{Eligibility criteria}

Papers eligible for inclusion were published in English after July 2010 (i.e., the end date of the previous systematic review) and reported on studies comparing rural versus urbandwelling cancer survivors in terms of their psychosocial morbidity or supportive care needs, or alternatively reported on these issues specifically for rural cancer survivors and/or their informal caregivers. Eligible studies included study participants who were adults (18 years or older) within a setting described as a regional or rural area(s) of Australia (i.e., the Accessibility/Remoteness Index of Australia (ARIA) as defined by the Australian Bureau of Statistics [27]), or as a rural area for countries of the developed world, as defined by the Human Development Index (HDI) of 0.8 or higher (i.e., high human development) [28]. The ARIA classifies locations into five categories: very remote, remote, moderately accessible, accessible, and highly accessible [27]. Both qualitative and quantitative (non-experimental) studies were included in the review. As per the previous review [23], studies were excluded if they did not report on the prevalence of psychosocial 
morbidity or supportive care needs, i.e., they were intervention studies, focussed on medical outcomes or survival rates, reported differences in the uptake of cancer screening or focussed on health attitudes or treatment decision making, and discussed service delivery or discussed the effectiveness of support groups or support via videoconferencing. In addition, studies were excluded if they explored psychosocial outcomes in indigenous populations (as the issues facing these populations are unique).

\section{Information sources}

Searches were identified via searching four electronic bibliographic databases, including RURAL: Rural and Remote Health Database (which specifically covers a range of subjects related to rural and remote area health issues and care), PsychINFO, Embase, and Medline. Additionally, backward and forward citation searching of all included articles was performed to identify any additional studies.

\section{Search strategy}

The searches were conducted in the final week of April 2020 and updated in the third week of May 2021. Search strategies were amended to the requirements of each database. In general, the searches included the following combinations of terms and were combined as (\#1 OR \#6) AND (\#2 OR \#7) AND (\#3 OR \#8) AND (\#4 OR \#9) NOT (\#5 OR \#10; Table 1). The search was limited to August 2010 until May 2021.

\section{Search selection}

Initial search results from all databases were screened for duplicates and eliminated through a systematic review management software (Covidence). Screening of articles was completed in two stages: of information provided in the title and abstract, and subsequently, full text. One reviewer (SK) screened all papers individually and the other reviewers screened a percentage in duplicate, $20 \%$ in the first stage $(\mathrm{KG})$ and $100 \%$ in the second stage. Any disagreement was resolved by discussion and where consensus could not be easily reached, a third independent reviewer (KS) made the final decision.

\section{Data collection and items}

Data extraction was conducted by one reviewer (SK). A second reviewer (KS) checked the data extracted from $20 \%$ of the articles to assess the quality of data collection. Additional data was extracted for one paper. As per the previous review [23], the included articles were summarised according to reference, study design, response rate, sample size, setting, measures, type of cancer, results, and study quality. In addition, data on study population was collected to allow for clearer documentation of whether study participants were adult cancer survivors undergoing treatment (i.e., people who were receiving cancer treatment at time of study - not including hormonal therapy), adult cancer survivors post-treatment (i.e., people who had finished cancer treatment at time of study), cancer patients in palliative care, and/or family or friends caring for a person with cancer.

\section{Risk of bias}

The quality of individual studies was assessed independently by two reviewers (SK and KS). Studies were critically appraised using the appropriate appraisal tool for the study design (both quantitative and qualitative), available from the Joanna Briggs Institute [29]. Included articles were categorised as having poor, good, or very good methodological reporting by calculating the percentages of items on which studies were rated as including essential quality characteristics (i.e., less than $40 \%$ were classified as poor, $40-70 \%$ as good,

Table 1 Search strategy*

\begin{tabular}{|c|c|c|c|}
\hline \multicolumn{2}{|c|}{$\begin{array}{l}\text { Medical Subject } \\
\text { Heading (MeSH) } \\
\text { terms }\end{array}$} & \multicolumn{2}{|c|}{ Text terms included in titles and/or abstract } \\
\hline 1 & Neoplasms & 6 & cancer OR neoplasm OR carcinoma OR oncology \\
\hline 2 & Rural population & 7 & regional OR remote OR travel \\
\hline 3 & 'Quality of life' & 8 & $\begin{array}{l}\text { well-being OR 'quality of life' OR QOL OR psycho* OR social OR emoti* OR } \\
\text { morbidity OR adjust* OR depress* OR anx* OR distress OR 'unmet needs' } \\
\text { OR need* }\end{array}$ \\
\hline 4 & Adult & 9 & $\begin{array}{l}\text { adult OR adults OR men OR women OR man OR woman OR elderly OR 'the } \\
\text { aged' OR 'middle aged' OR senior* OR geriatric* }\end{array}$ \\
\hline 5 & $\begin{array}{l}\text { Oceanic ancestry } \\
\text { group }\end{array}$ & 10 & aborigi* OR indigenous* \\
\hline
\end{tabular}

*Combined as (\#1 OR \#6) AND (\#2 OR \#7) AND (\#3 OR \#8) AND (\#4 OR \#9) NOT (\#5 OR \#10) 
and higher than $70 \%$ as very good). Studies that combined qualitative and quantitative methods (i.e., mixed methods) were assessed by the Mixed Methods Appraisal Tool (MMAT) [30]. Any initial differences (17\%) were resolved through discussion and consensus. Studies of all levels of quality were included in the data synthesis.

\section{Summary measures}

Levels of psychosocial morbidity and quality of life (QOL) were measured in proportions. The unmet needs and experiences of people with cancer were documented thematically.

\section{Results}

\section{Study selection}

The search of electronic databases identified 4589 unique papers published online since August 2010 (Figure 1). After removal of duplicates, 4332 studies remained and were evaluated on title and abstract. A total of 259 potentially relevant papers were assessed on full text, of which 61 papers were included. Four additional papers were identified through backward and forward citation searching, resulting in 65 studies being included in this systematic review (August 2010 May 2021).

\section{Study characteristics}

Characteristics of studies identified through the systematic review are presented in Tables 2, 3, 4, 5, 6. Of the 20 qualitative studies included, data collection methods included oneon-one interviews ( $n=14)$, focus groups $(n=2)$, and combined interviews and focus groups $(n=4)$. Of these 20 studies, ten were conducted in Australia, five in the US, four in Canada, and one in Europe. Most studies focussed on a variety of cancer types $(n=10)$, three each on breast and haematological cancers, two on gynaecological cancer, and one each on prostate and myeloma cancer.

Among quantitative studies, 35 utilised a cross-sectional study design while six studies employed a longitudinal study methodology. Of these 41 studies, 18 were conducted in Australia, 16 in the US, six in Europe, and one in Canada. Most studies $(n=18)$ included participants with heterogenous cancers, eight with breast cancer, five with haematological
Figure 1 PRISMA study selection flowchart
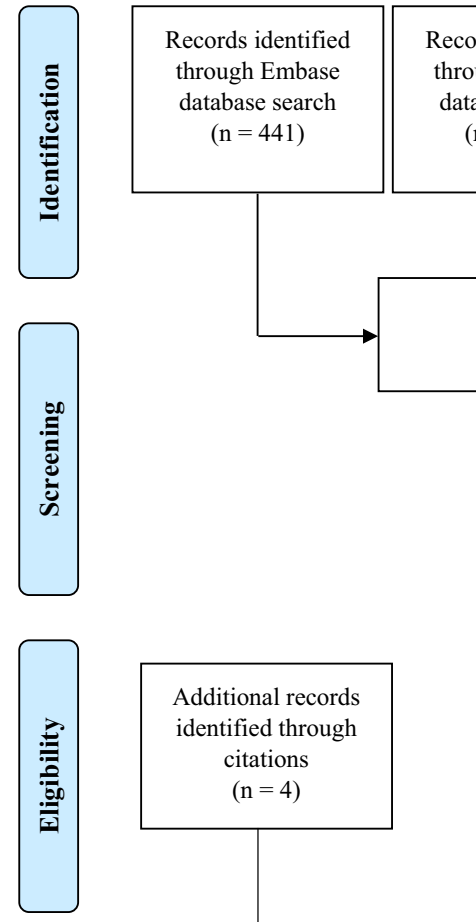

Additional records identified through citations

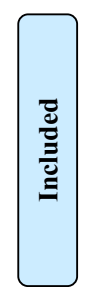
$(n=4)$

$$
(\mathrm{n}=
$$

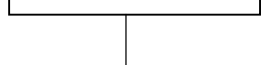

Records identified through Medline database search ( $\mathrm{n}=3745$ )

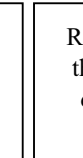

Records identified
through PsycInfo database search $(\mathrm{n}=231)$
Records identified through RURAL database search $(\mathrm{n}=172)$
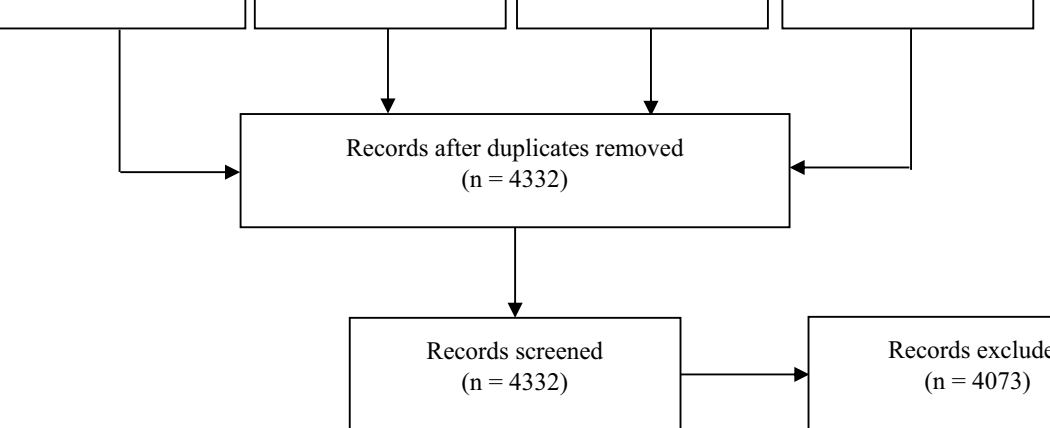

Full-text articles excluded, with reasons $(\mathrm{n}=198)$ :

- $\quad$ Not a primary study $(\mathrm{n}=$ 11)

- Design was not descriptive/ nonexperimental $(\mathrm{n}=8)$

- Not described as a rural cancer population $(\mathrm{n}=$ 86)

- Not focused on psychosocial morbidity or needs $(\mathrm{n}=86)$

Studies included in qualitative synthesis $(n=65)$

- Not a developed country $(n=4)$

- Other reasons $(\mathrm{n}=3)$ 


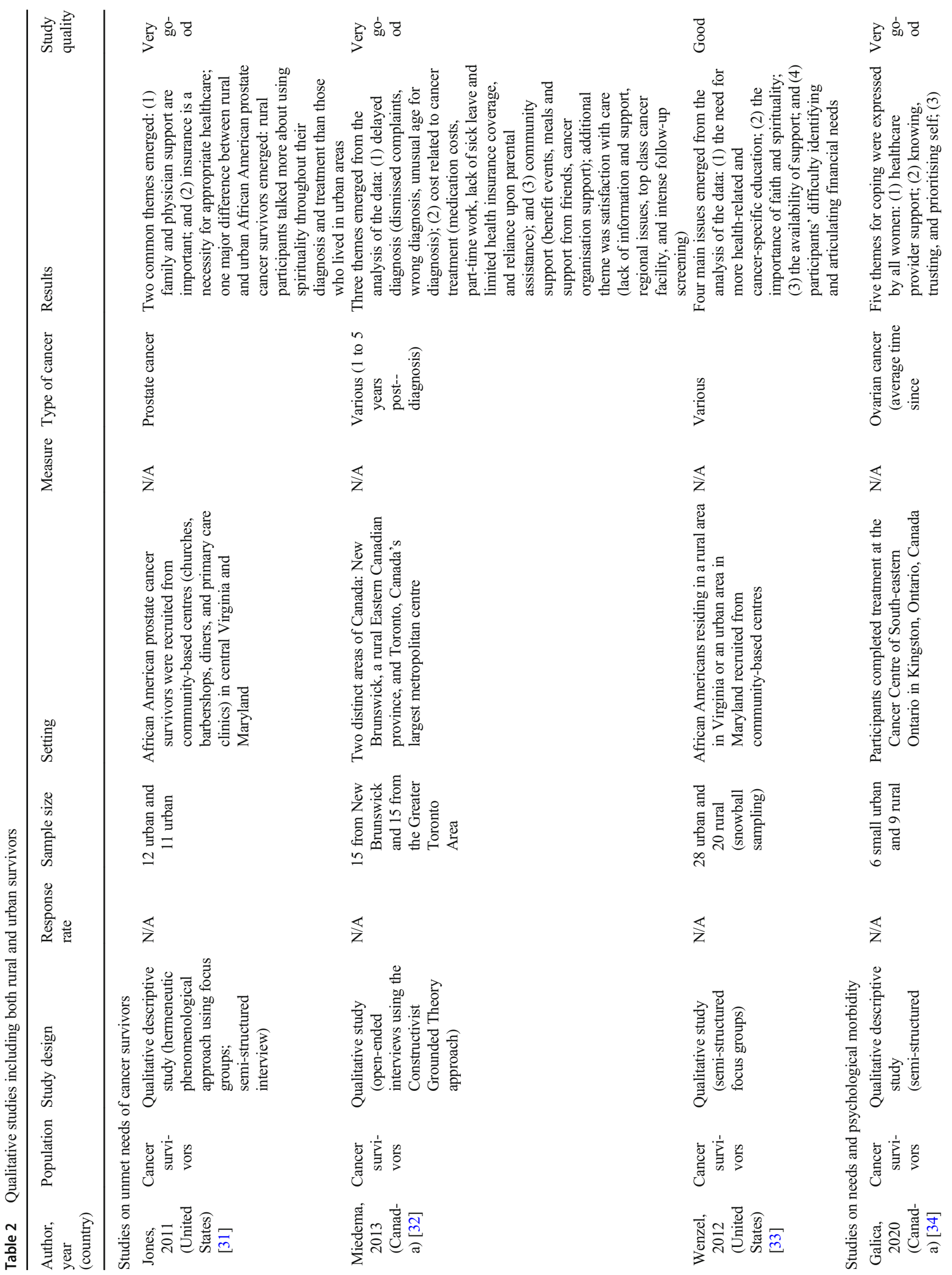




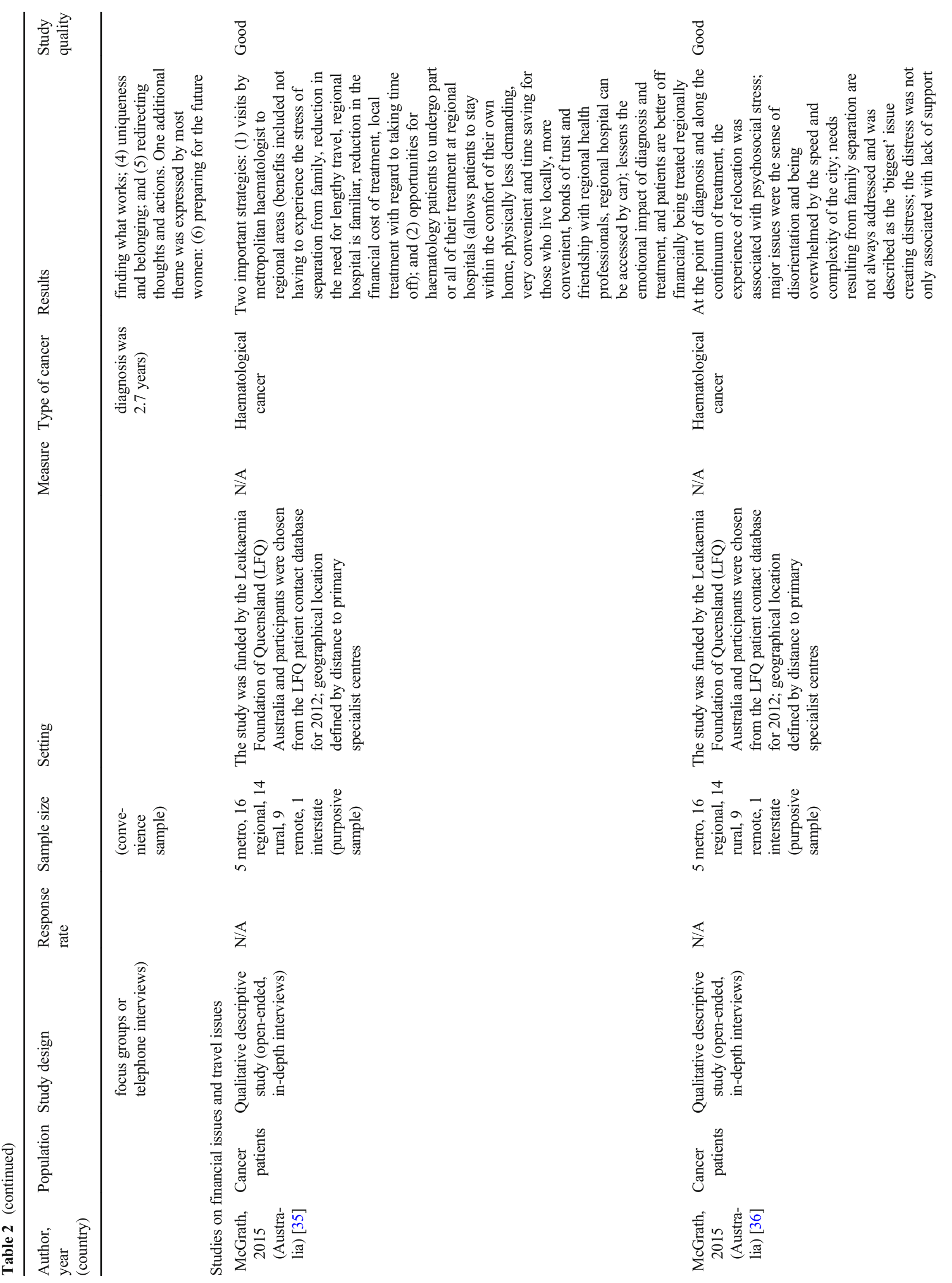




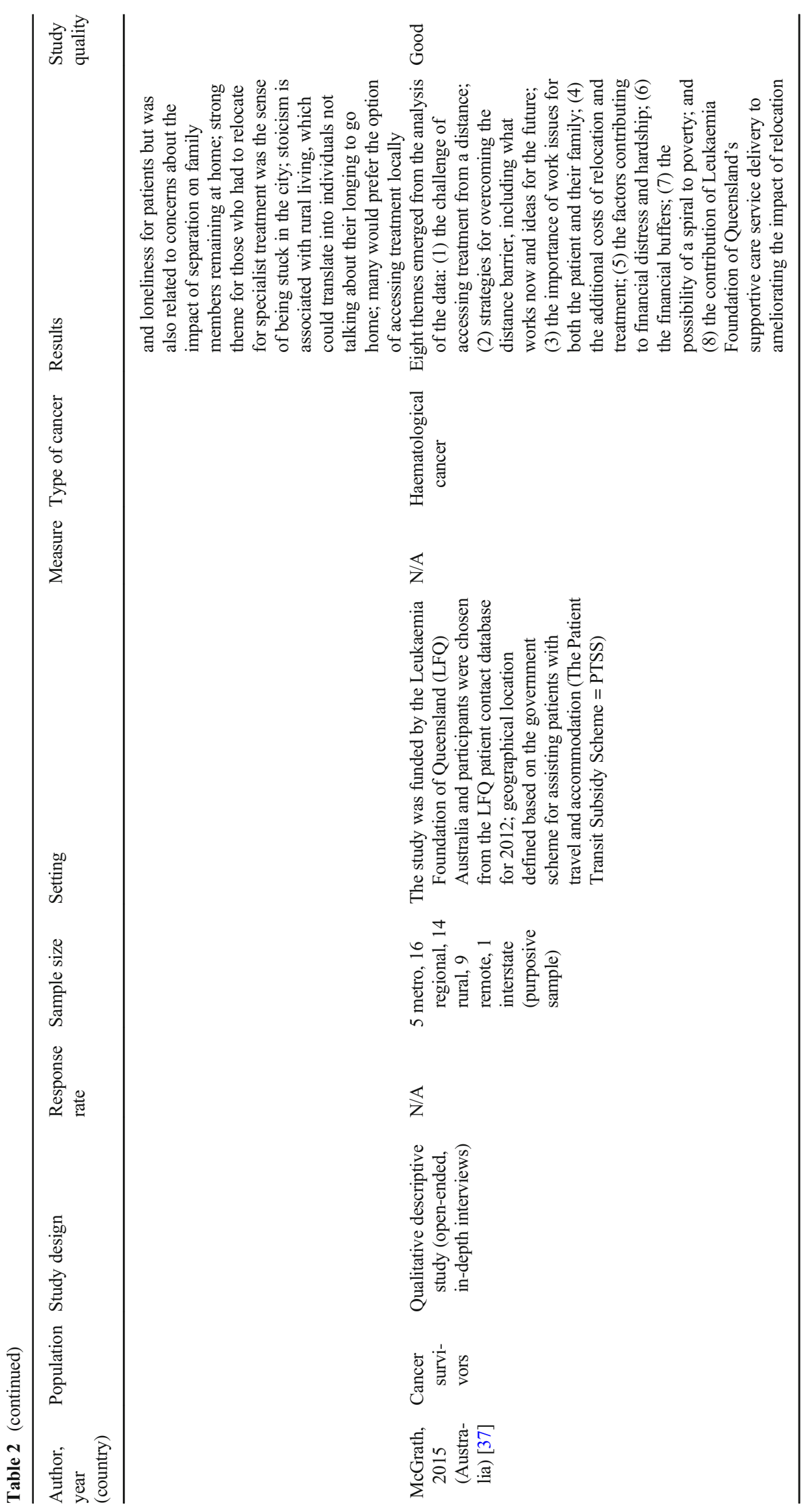




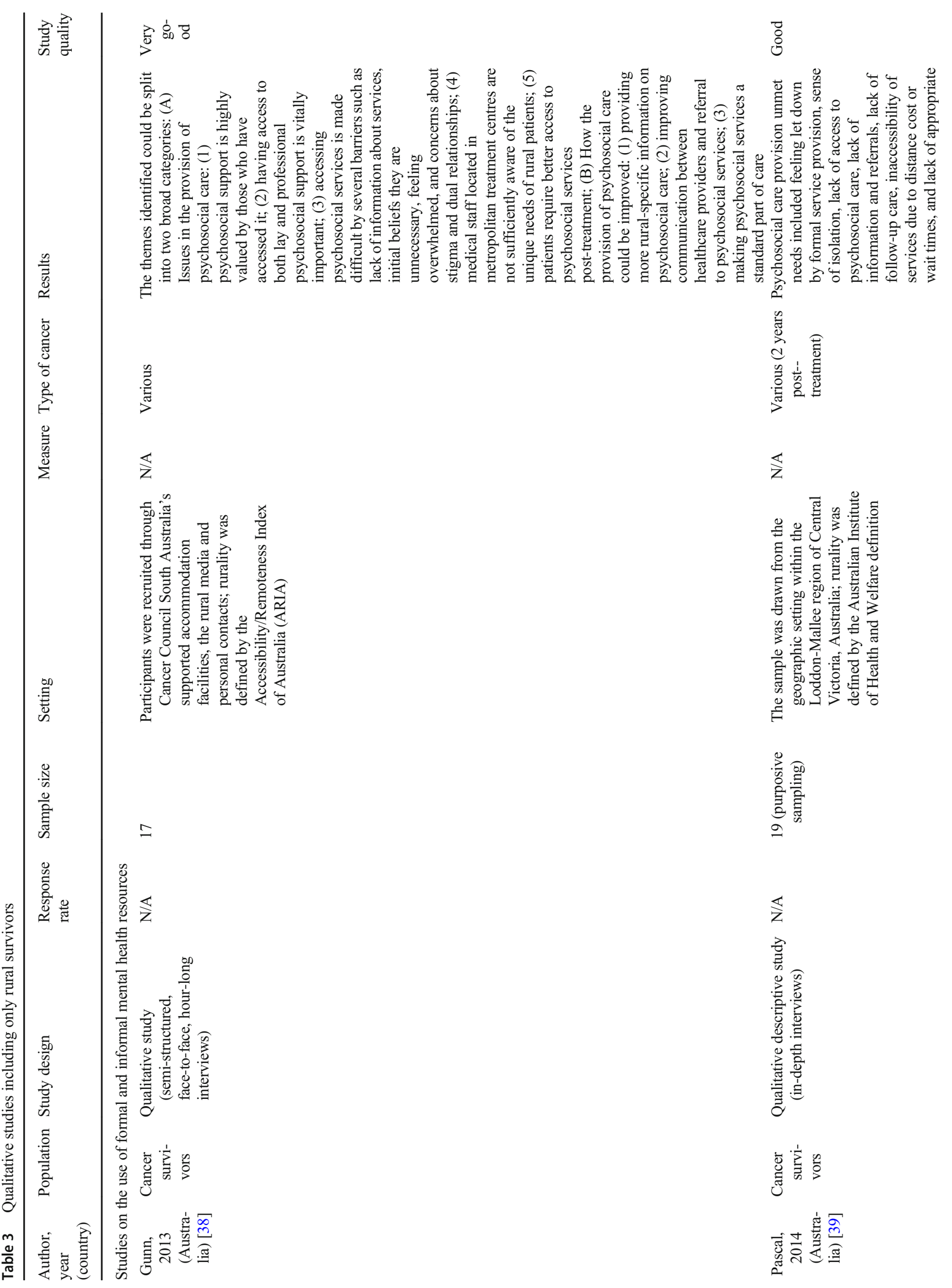




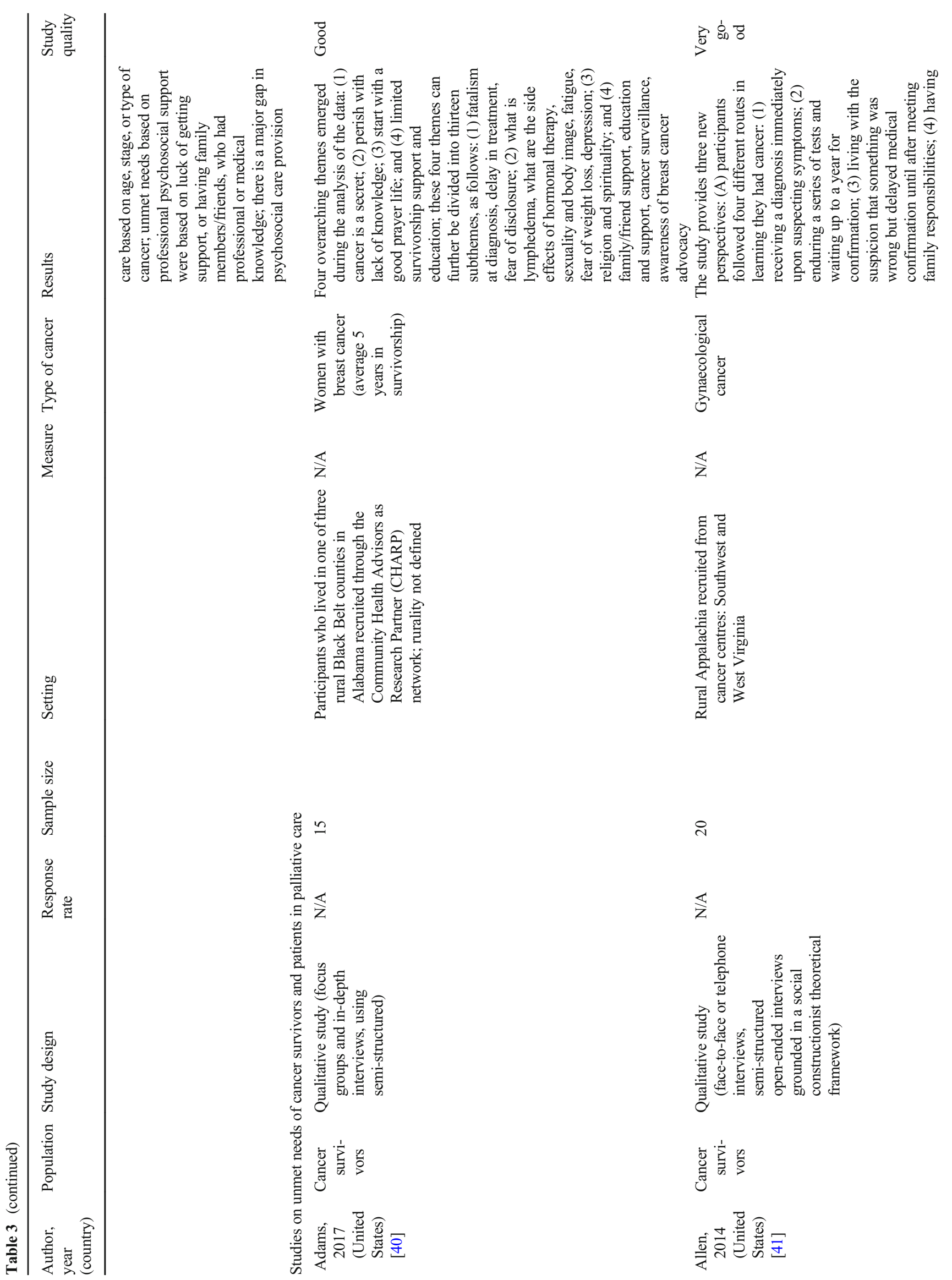




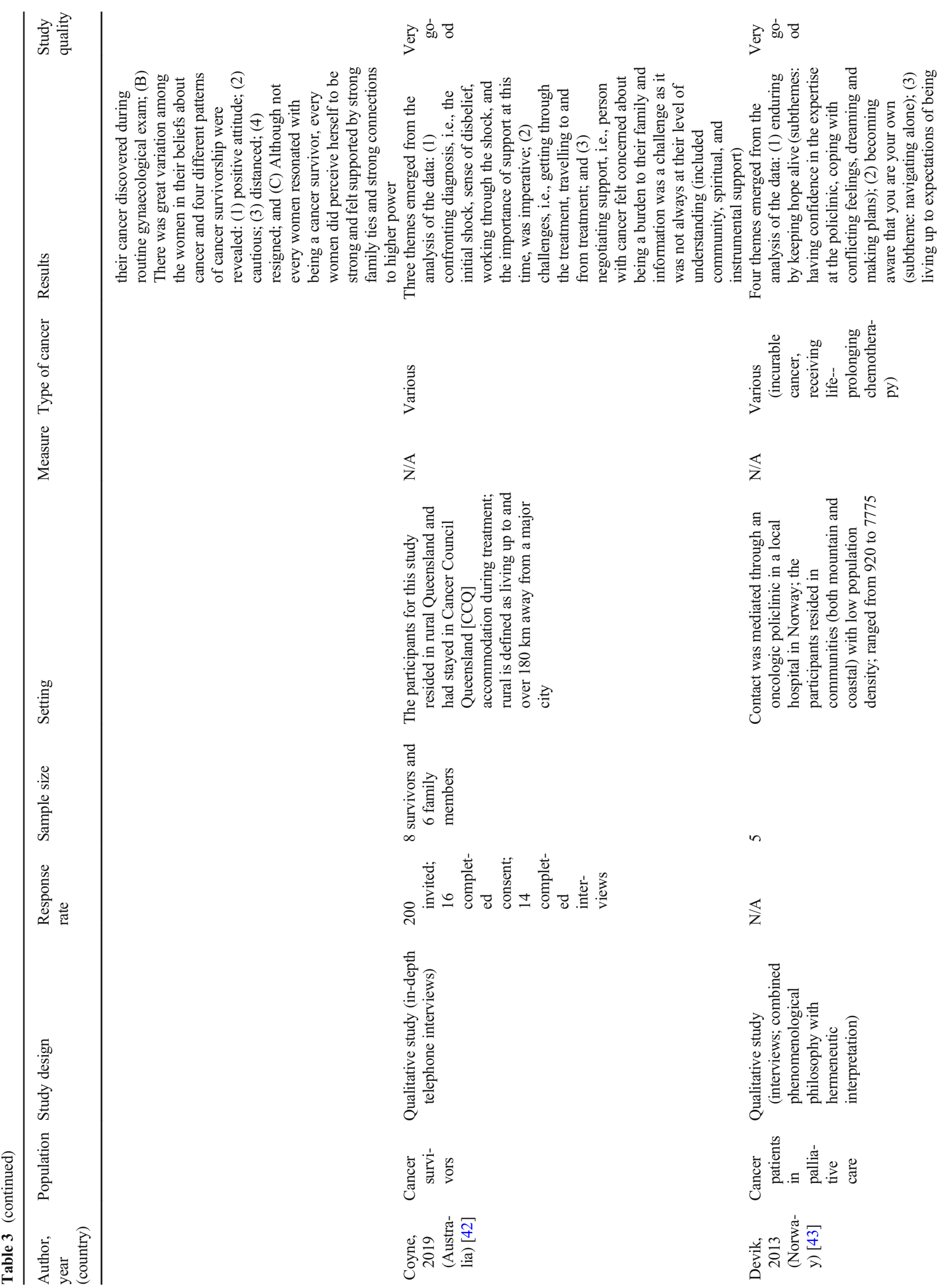




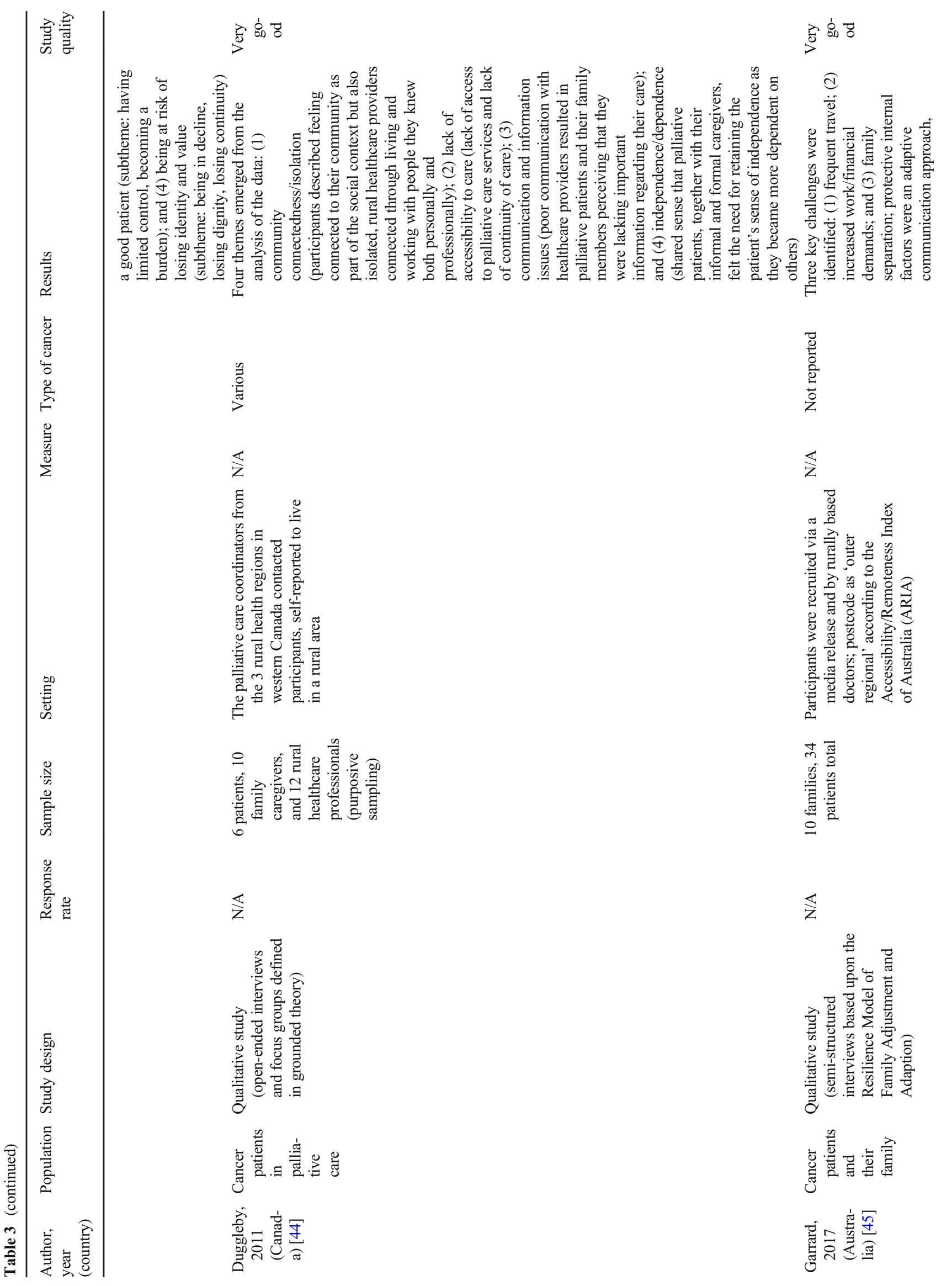




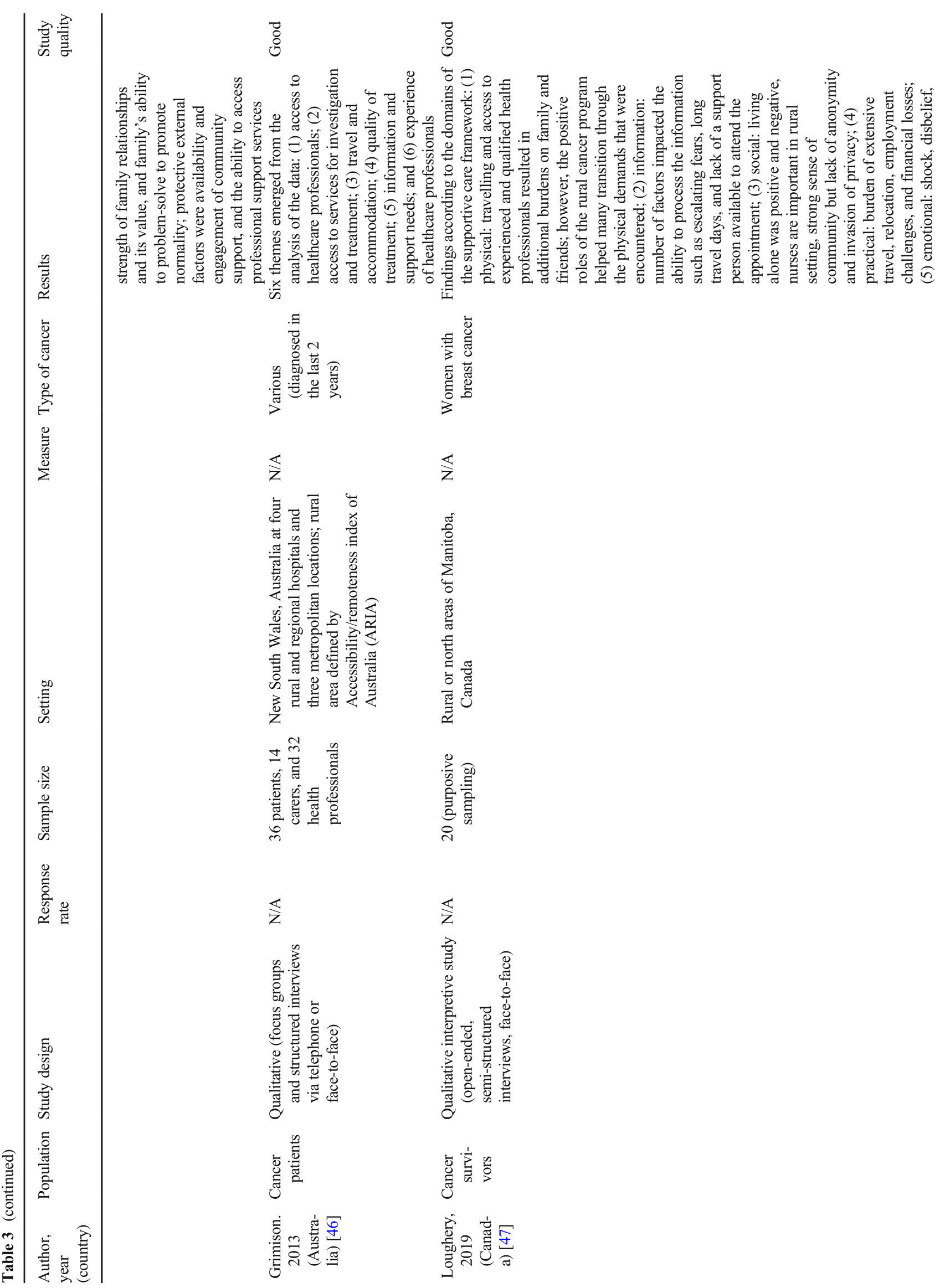




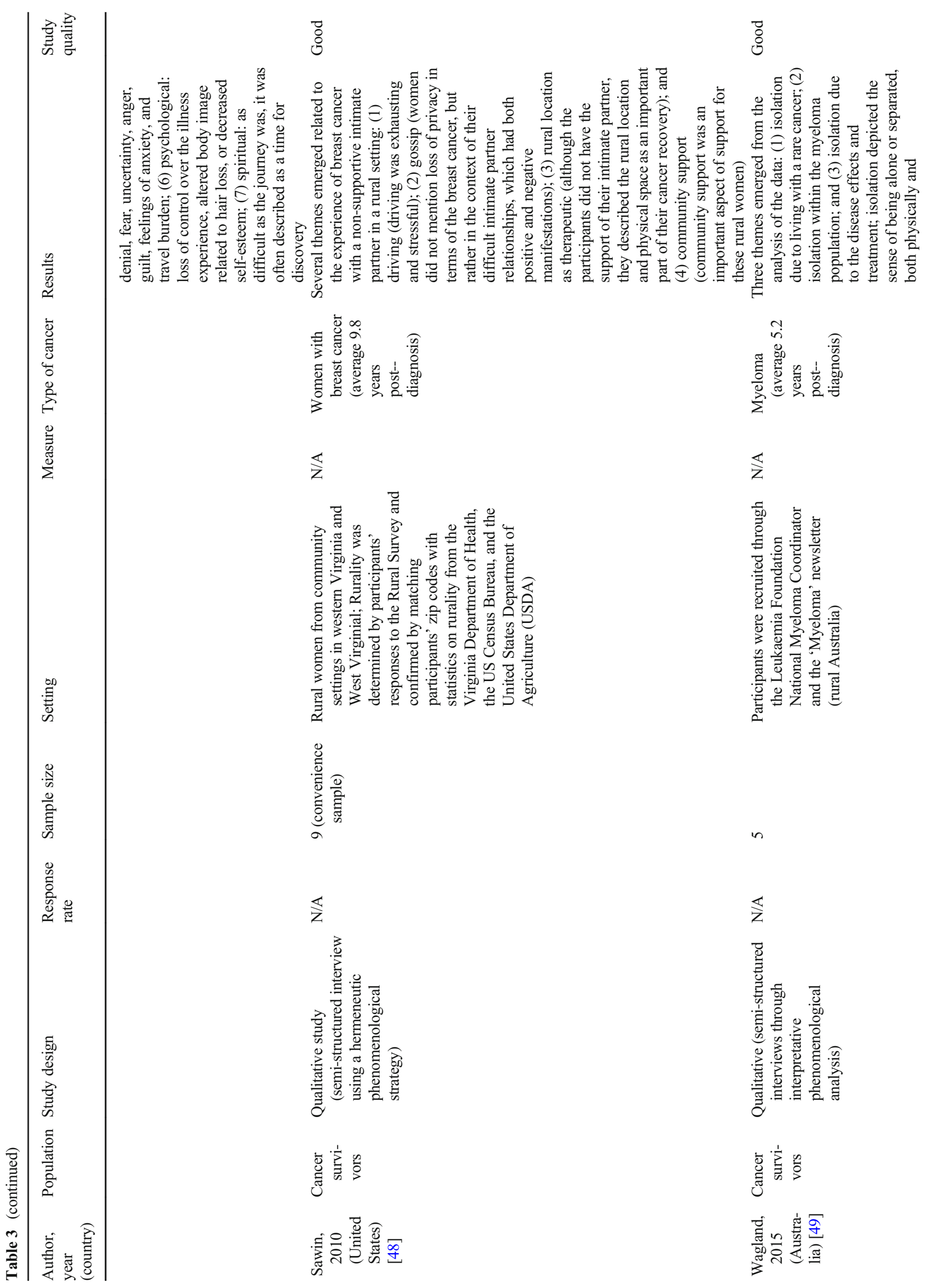




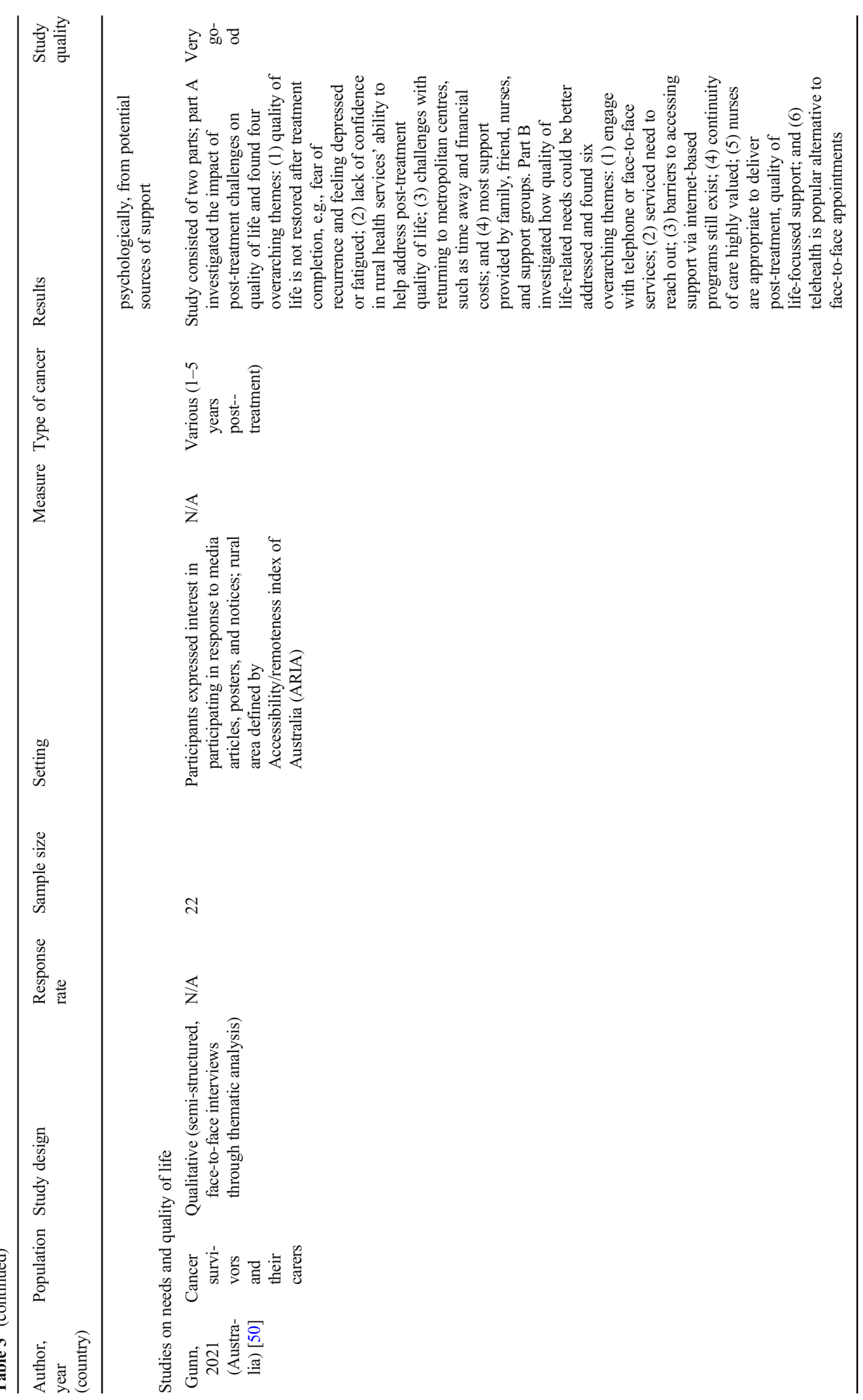




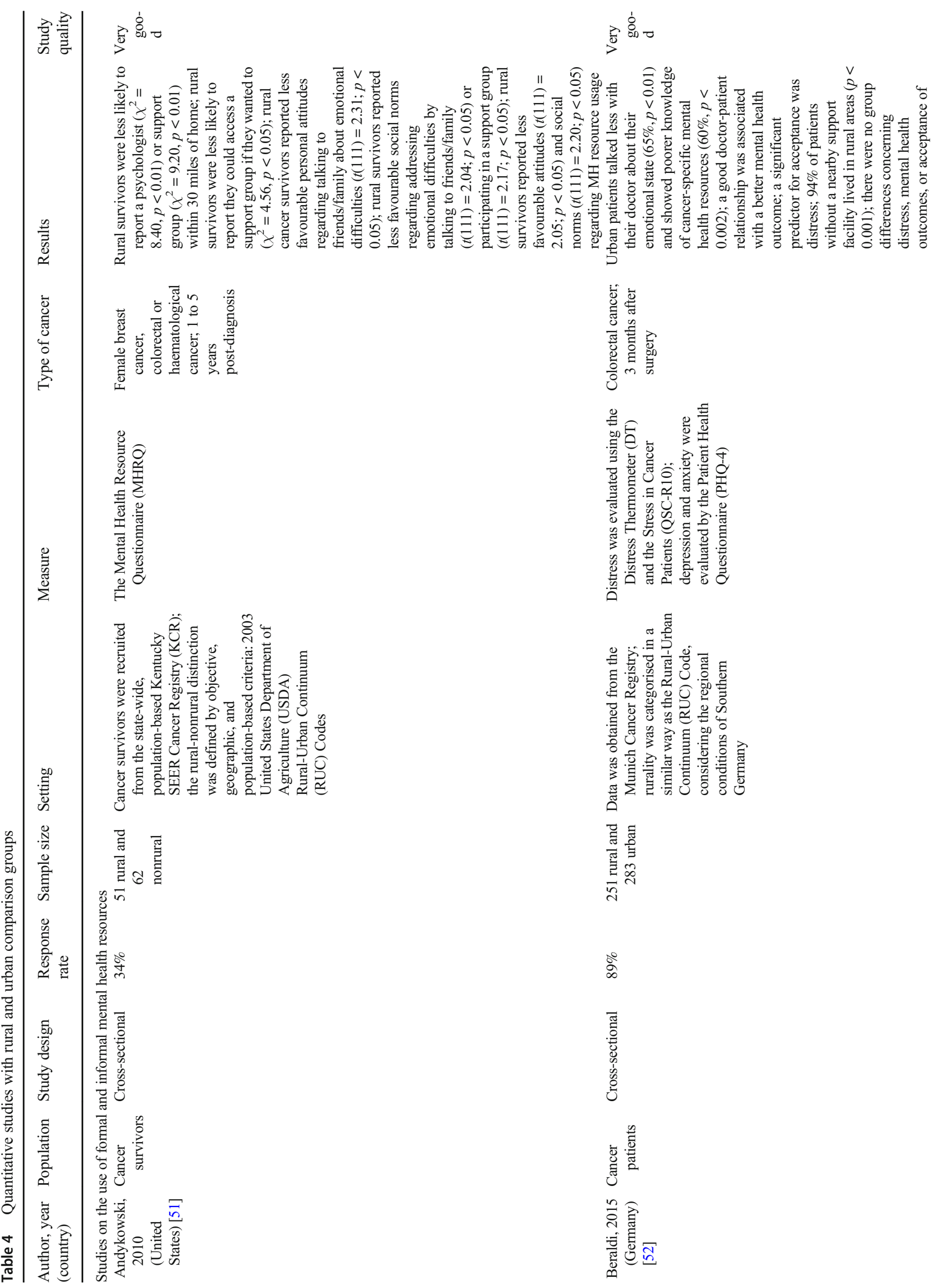




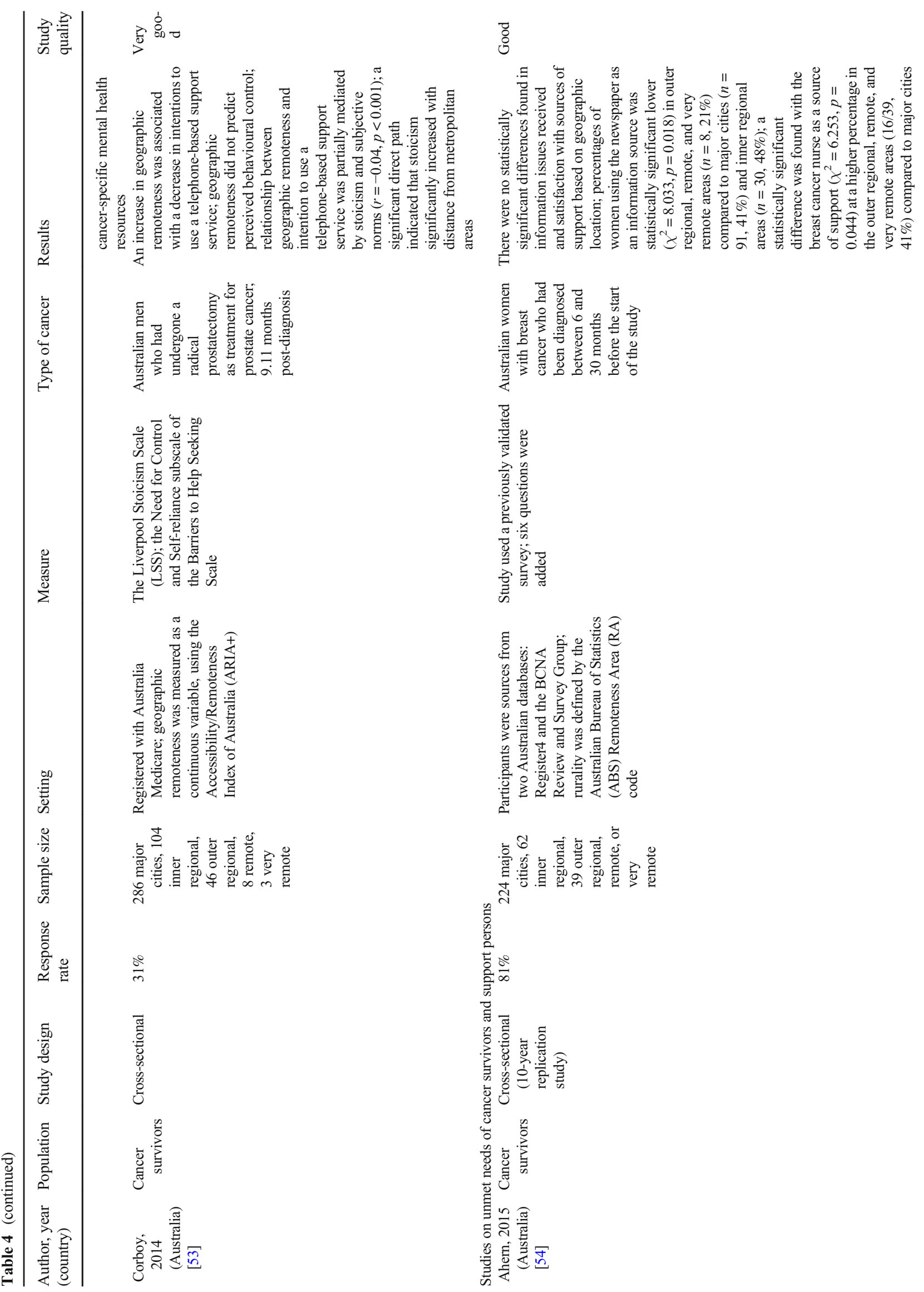




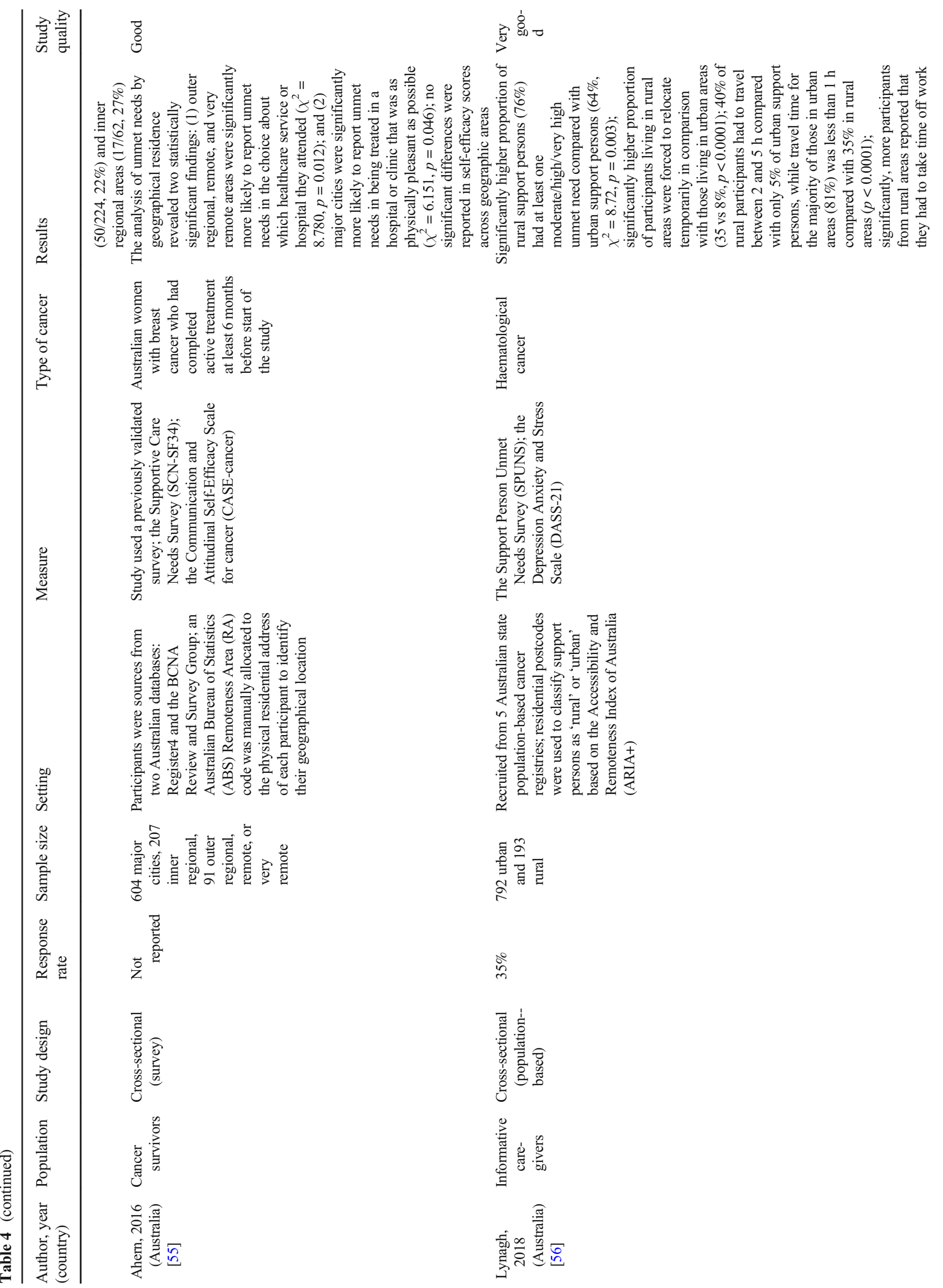




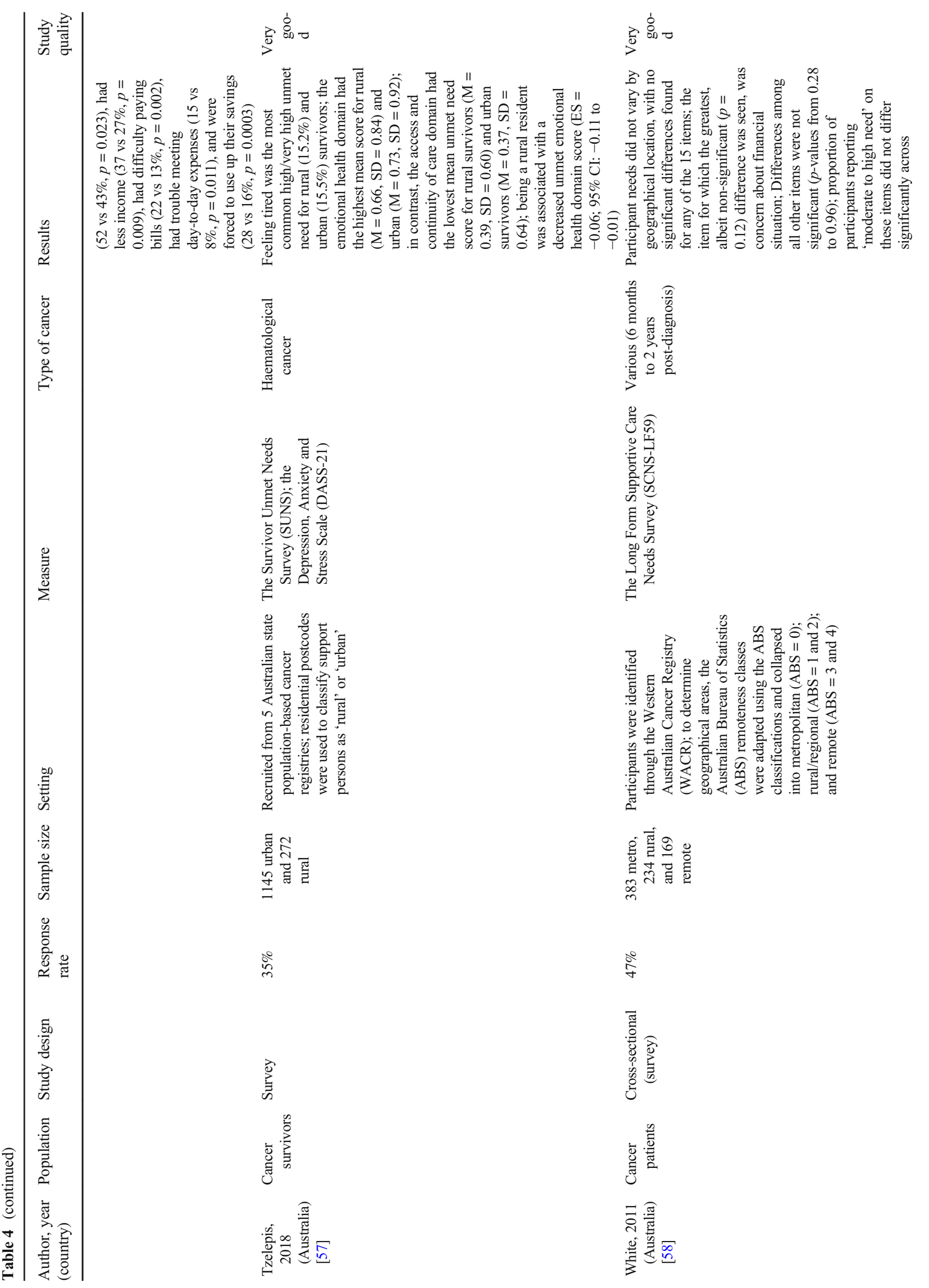




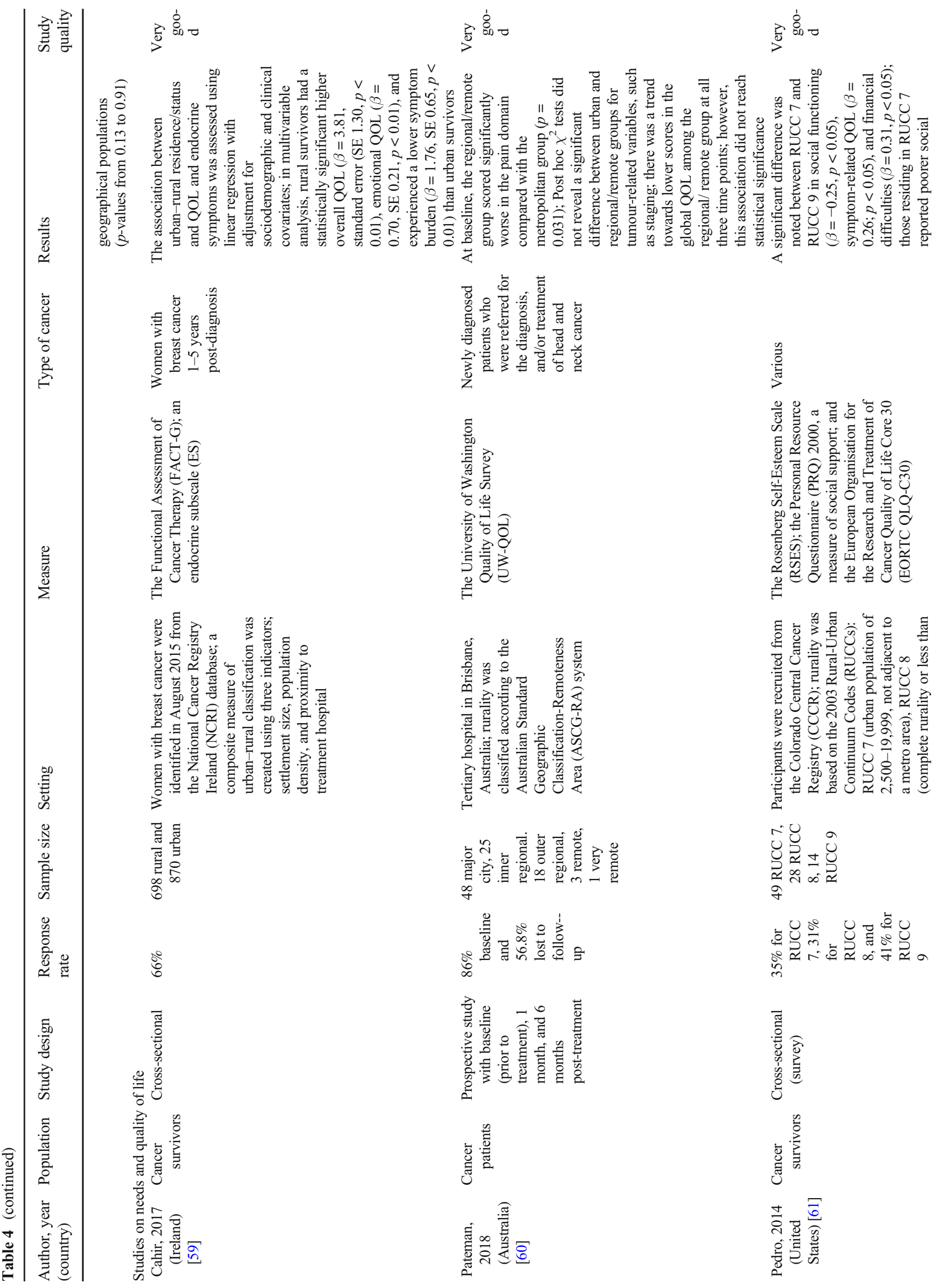




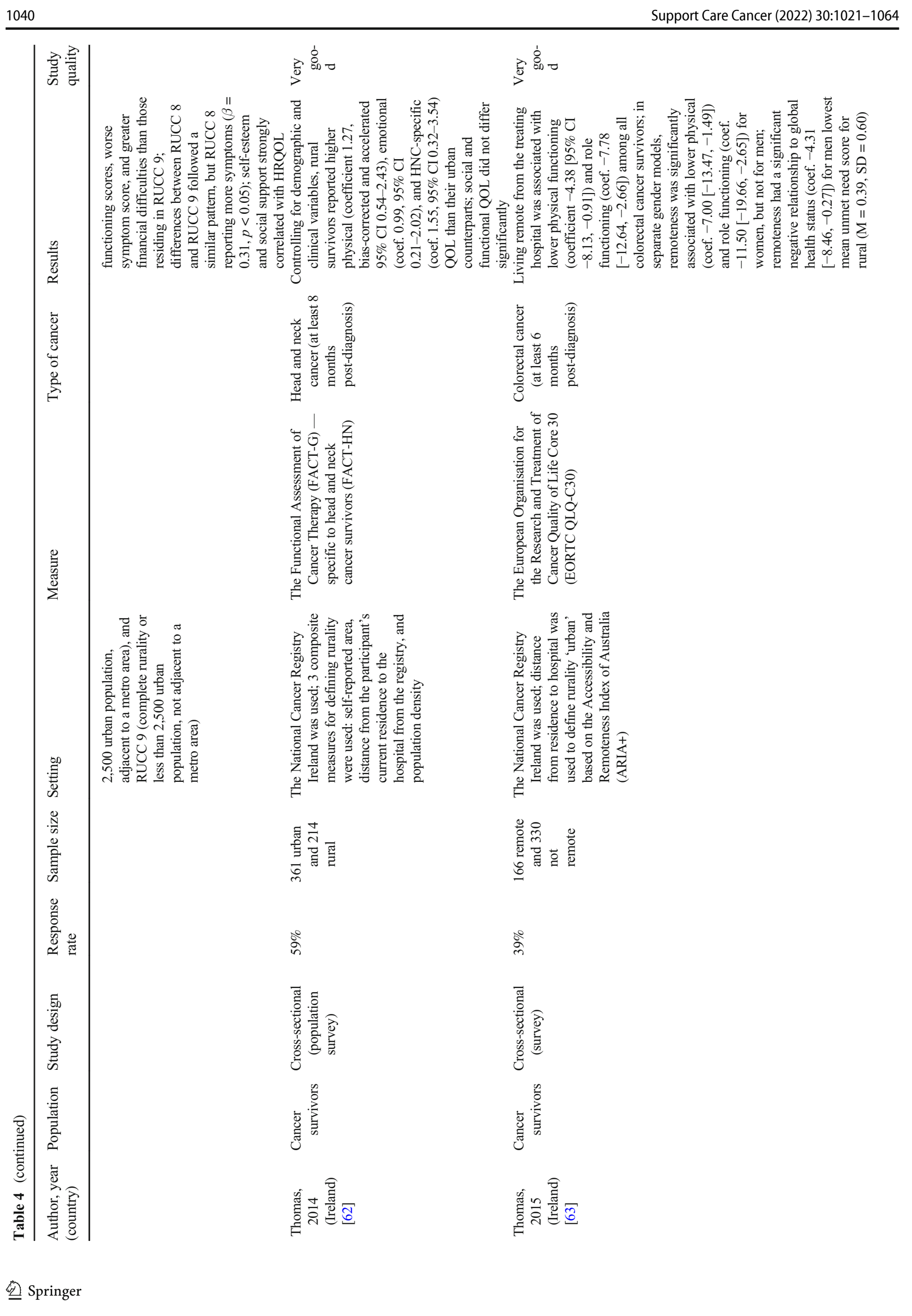




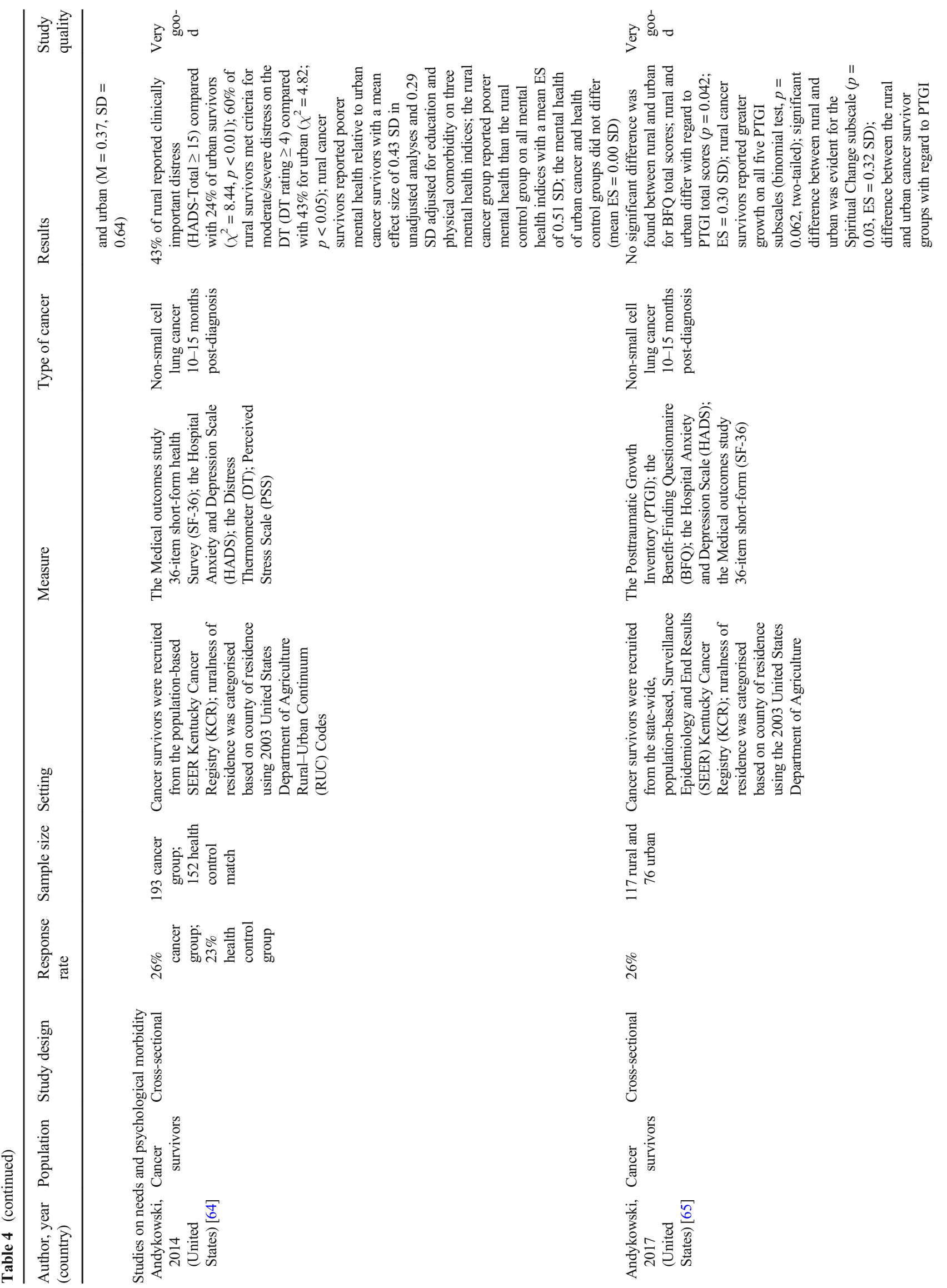




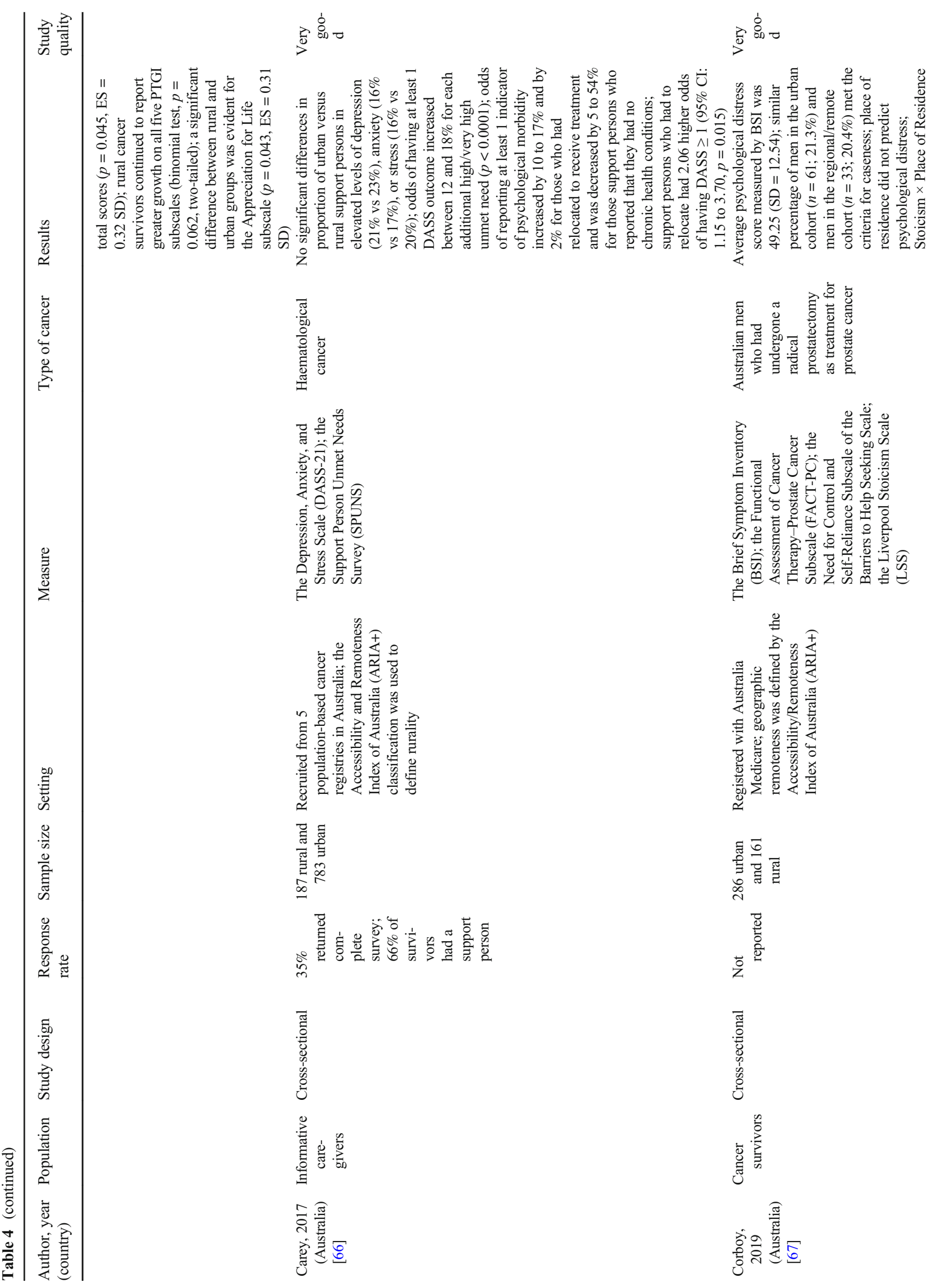




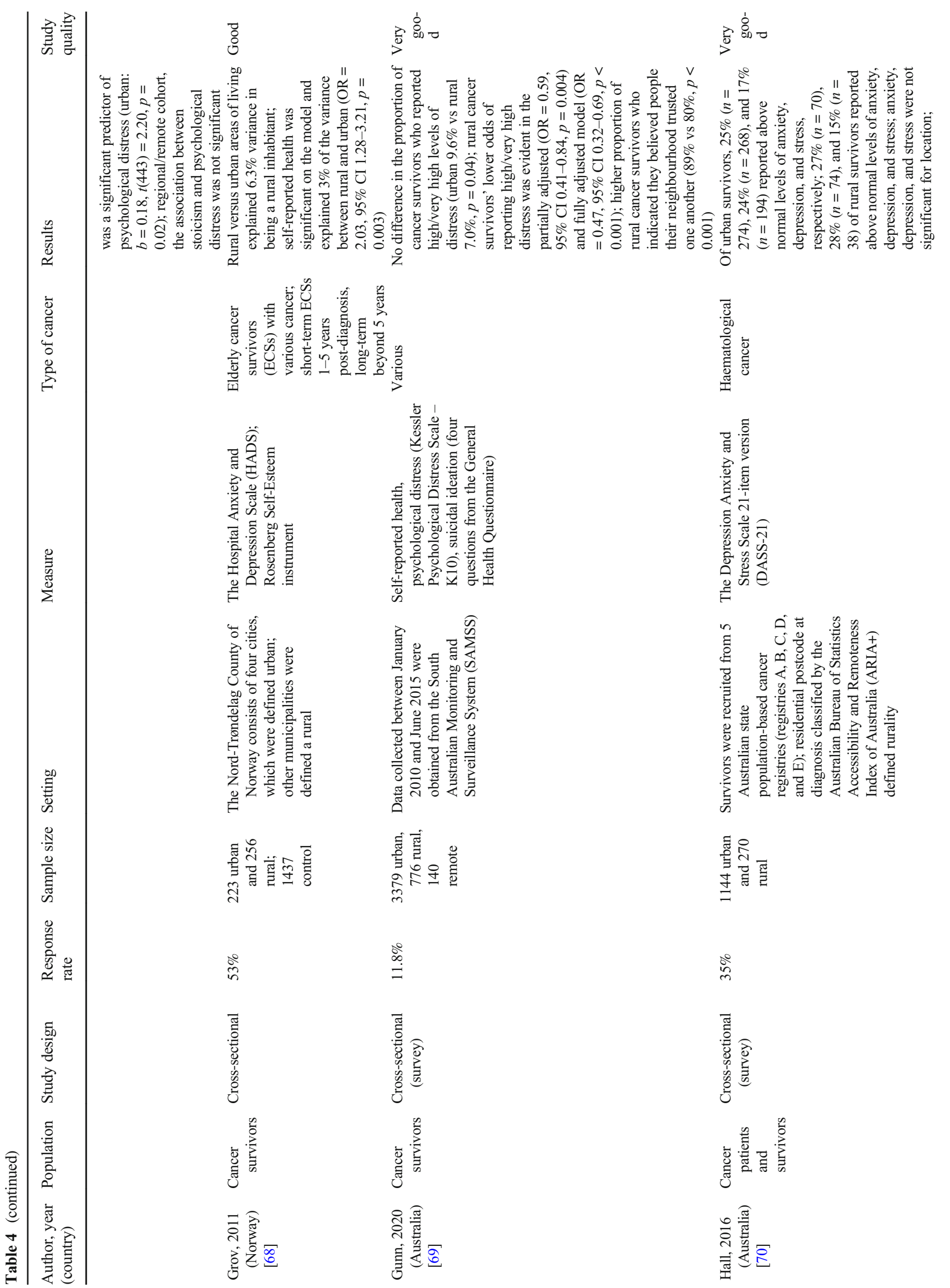




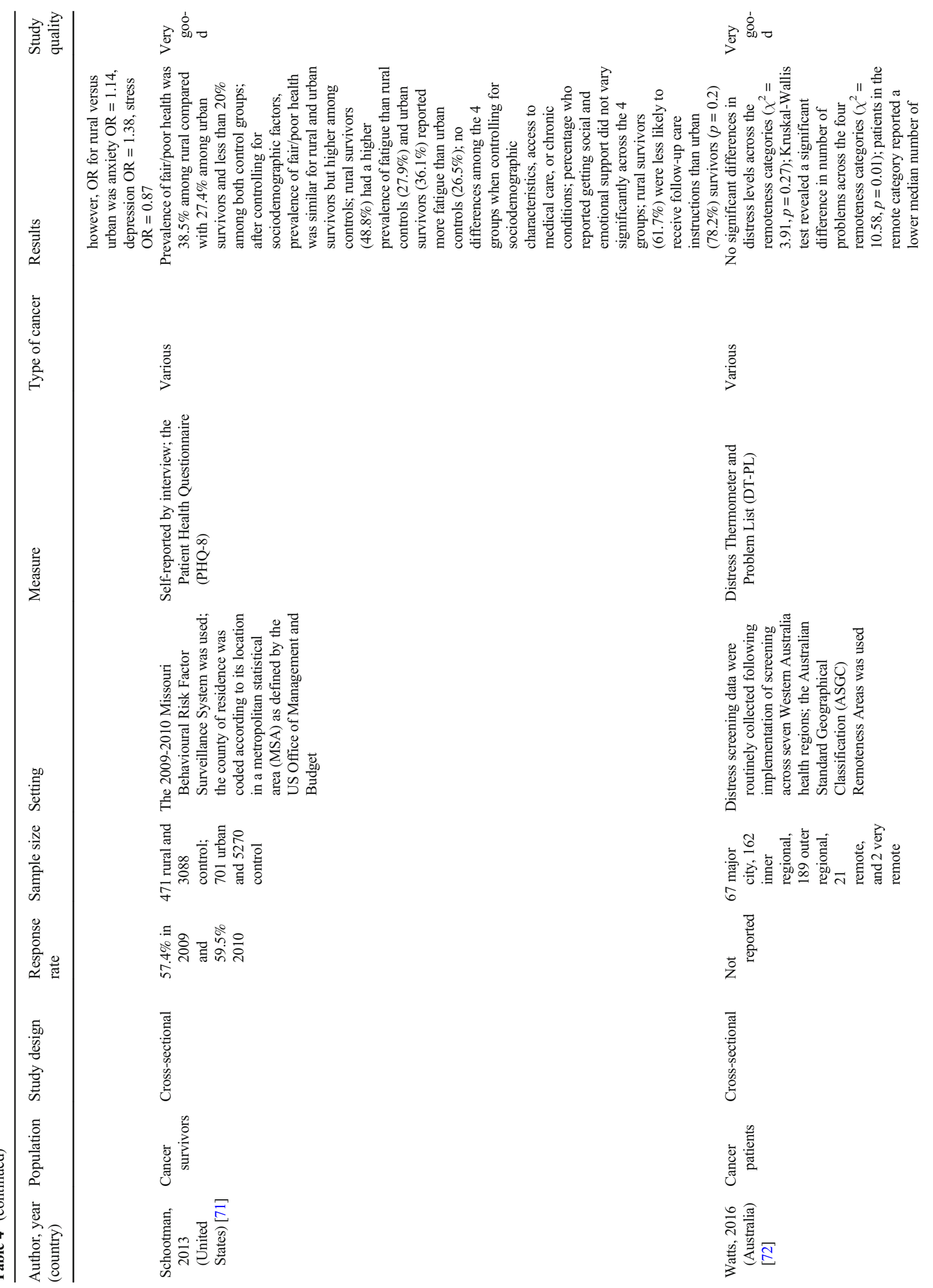




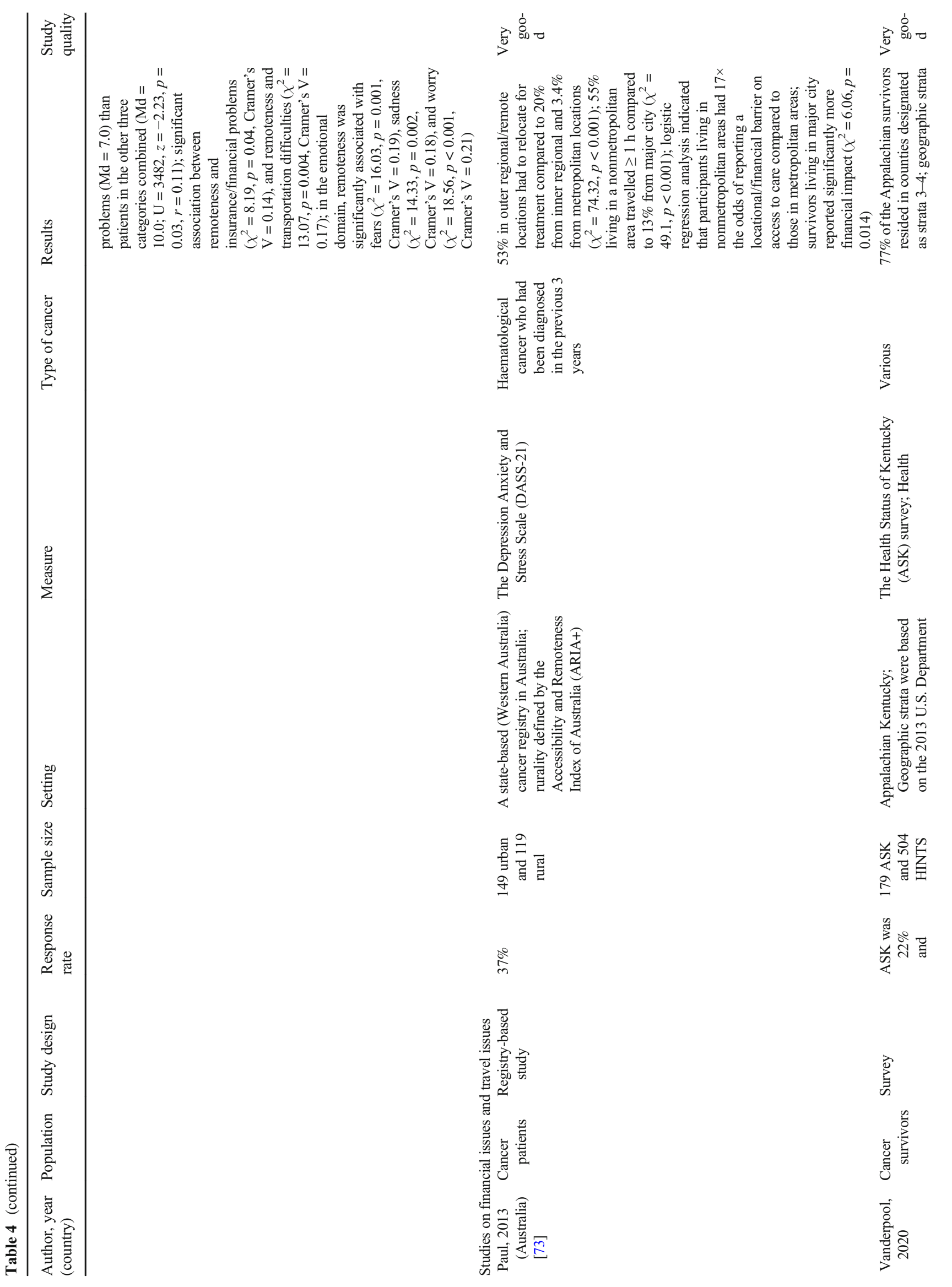




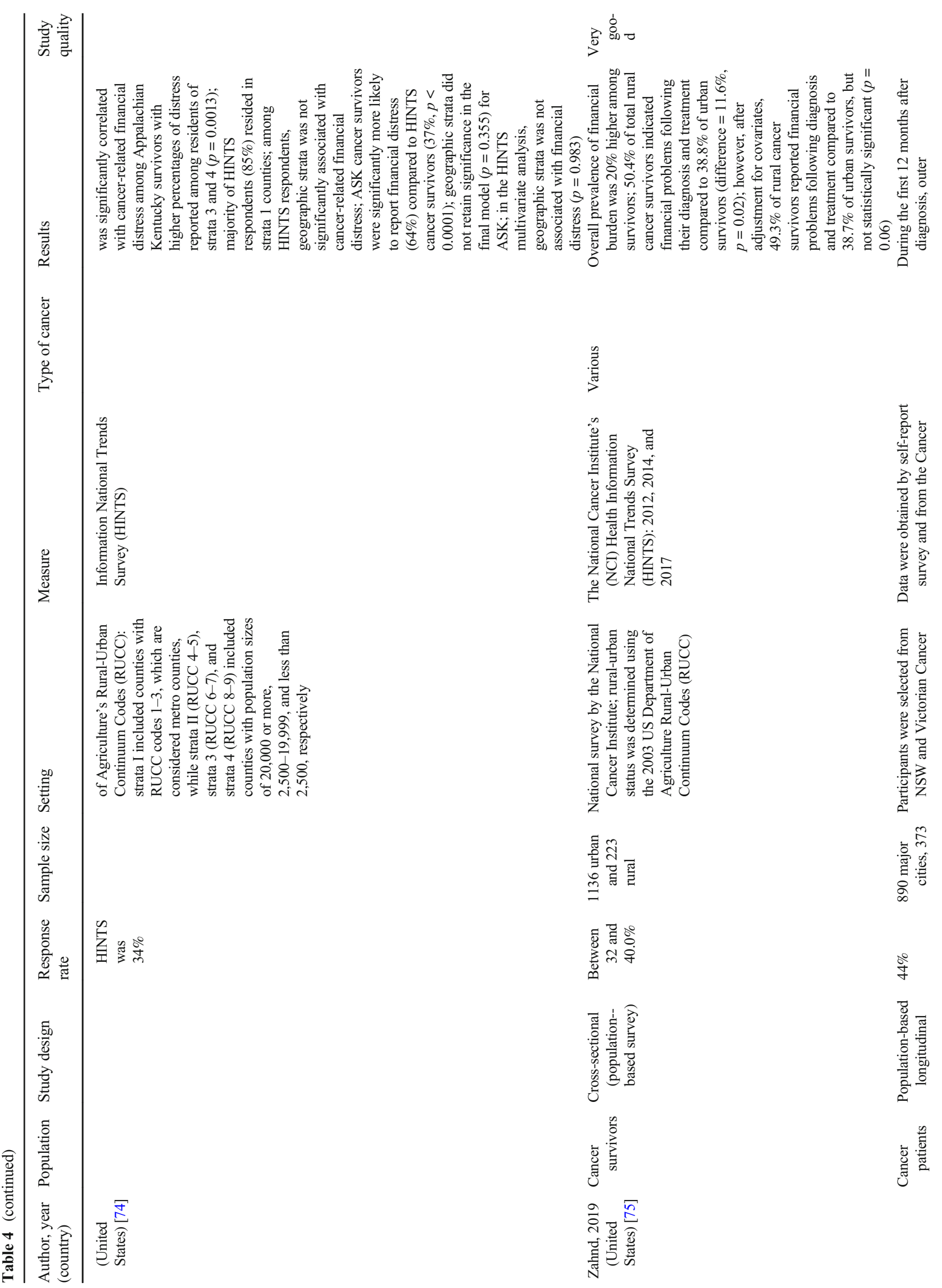




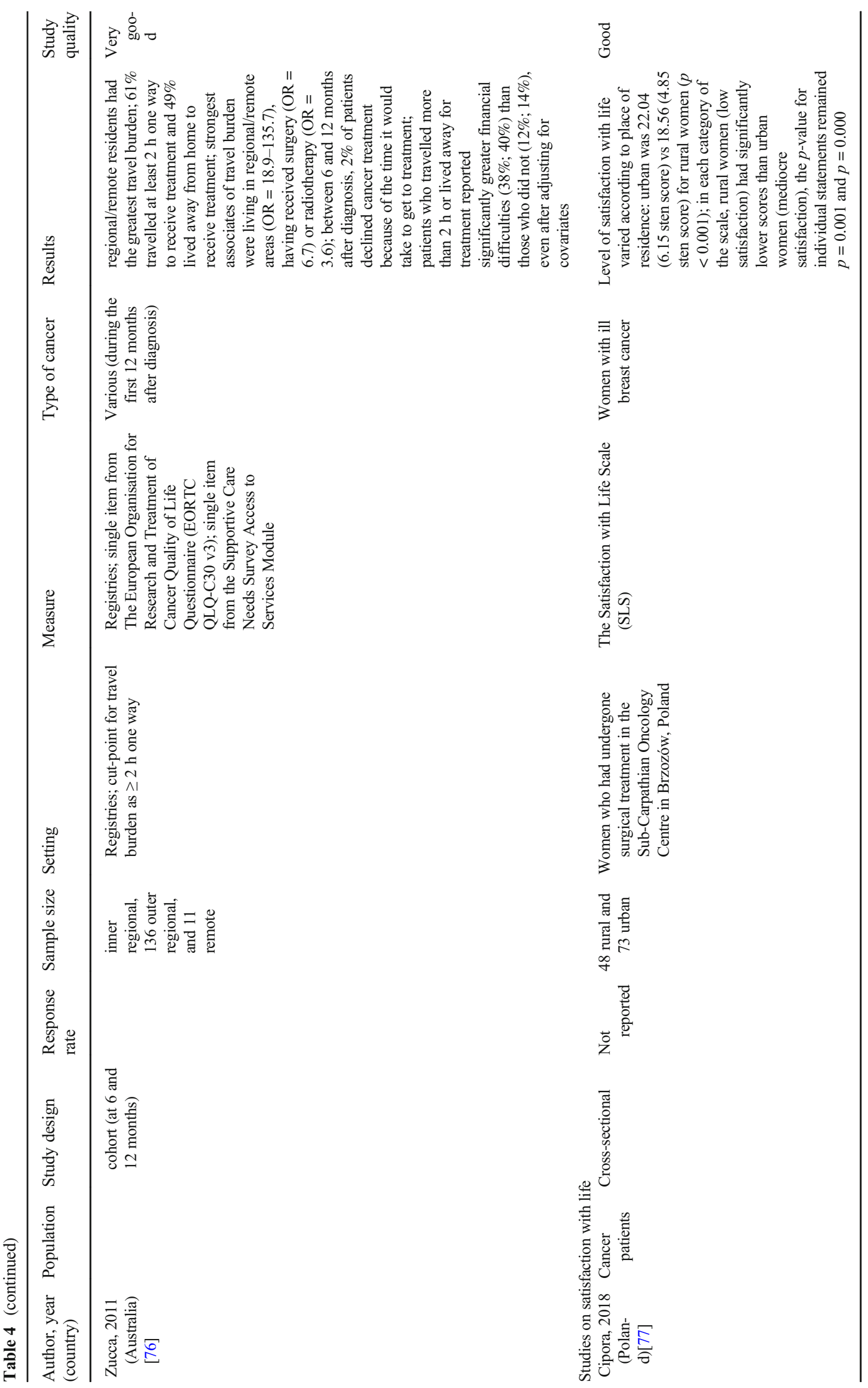




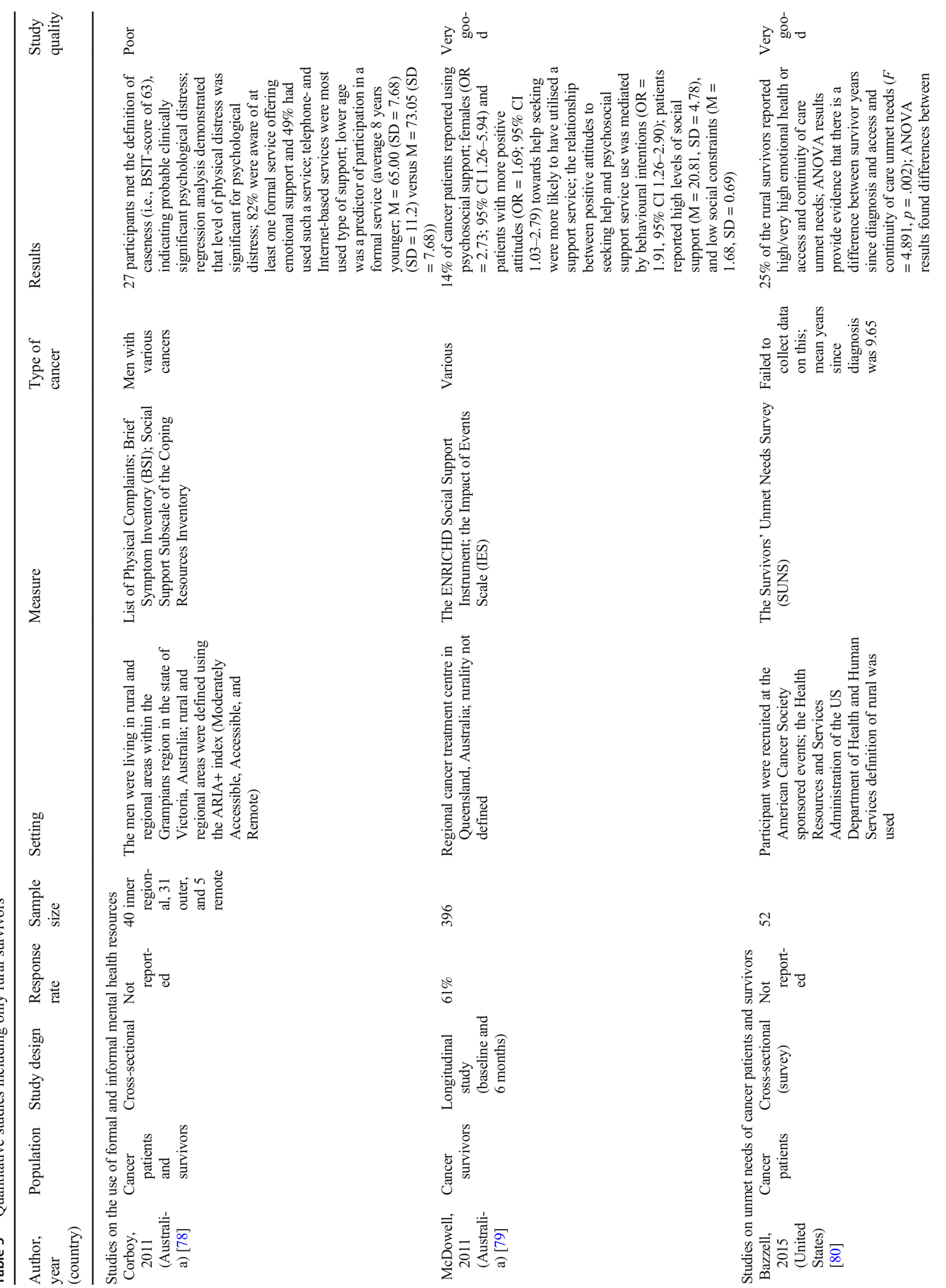




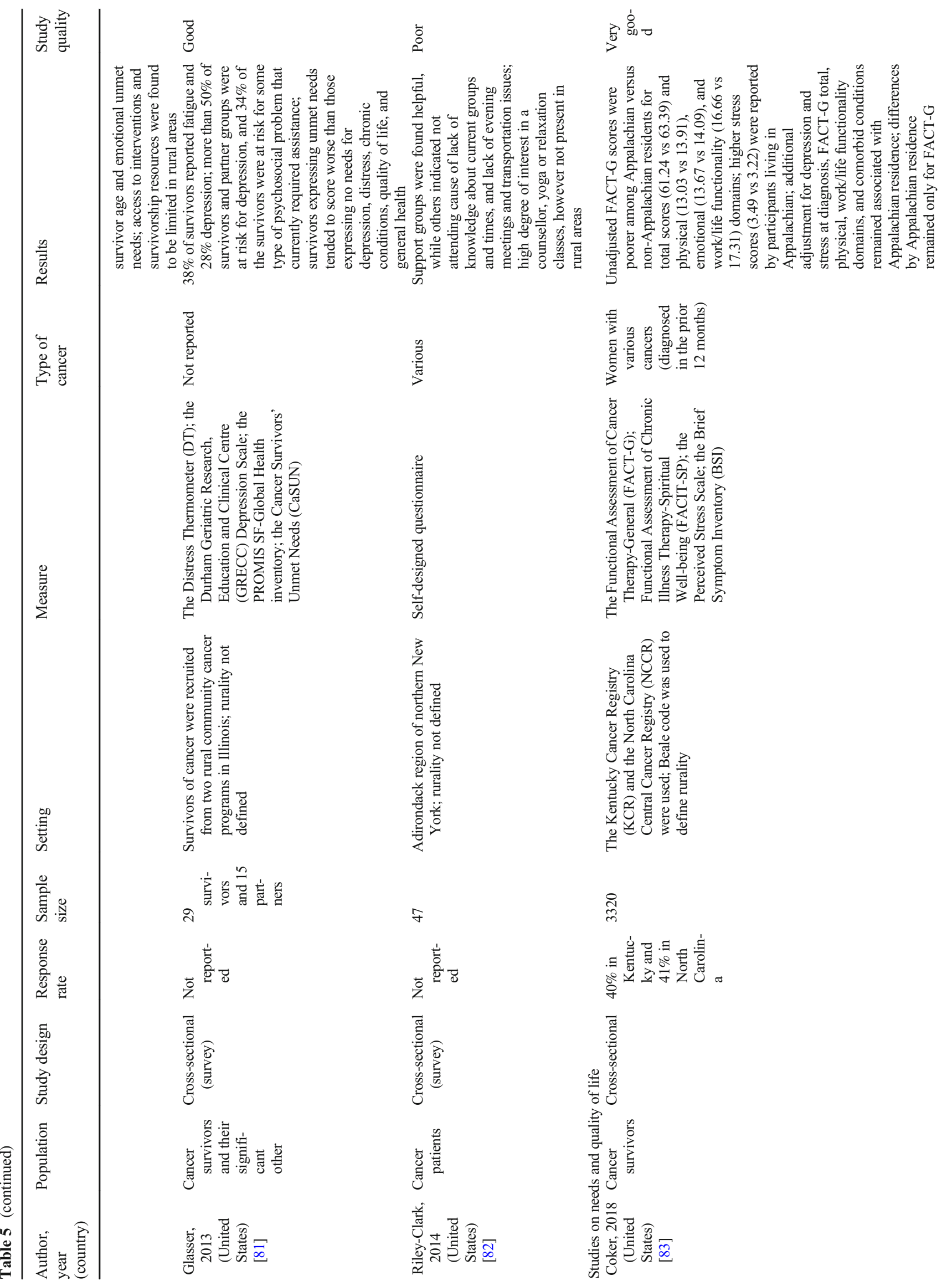




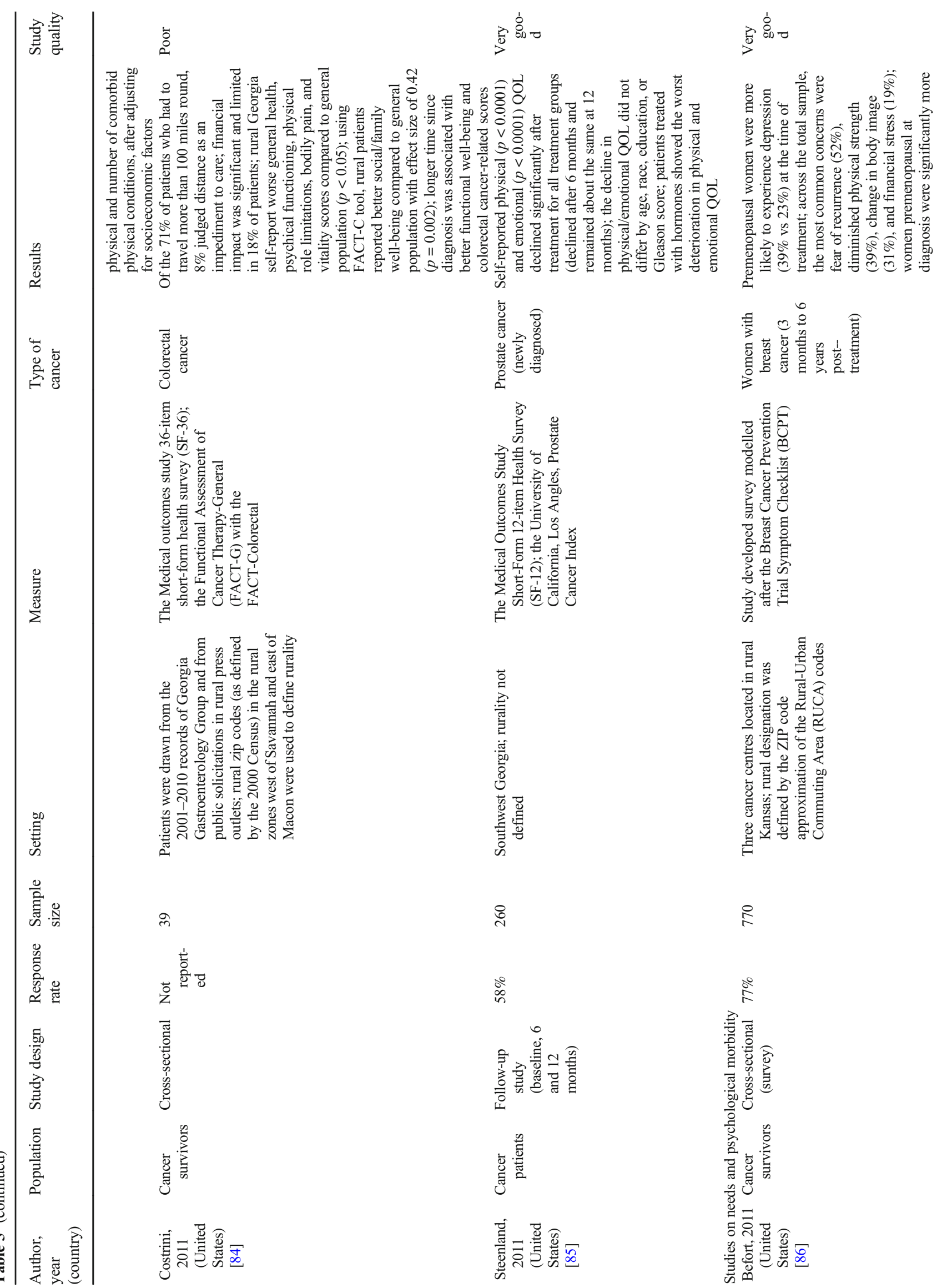




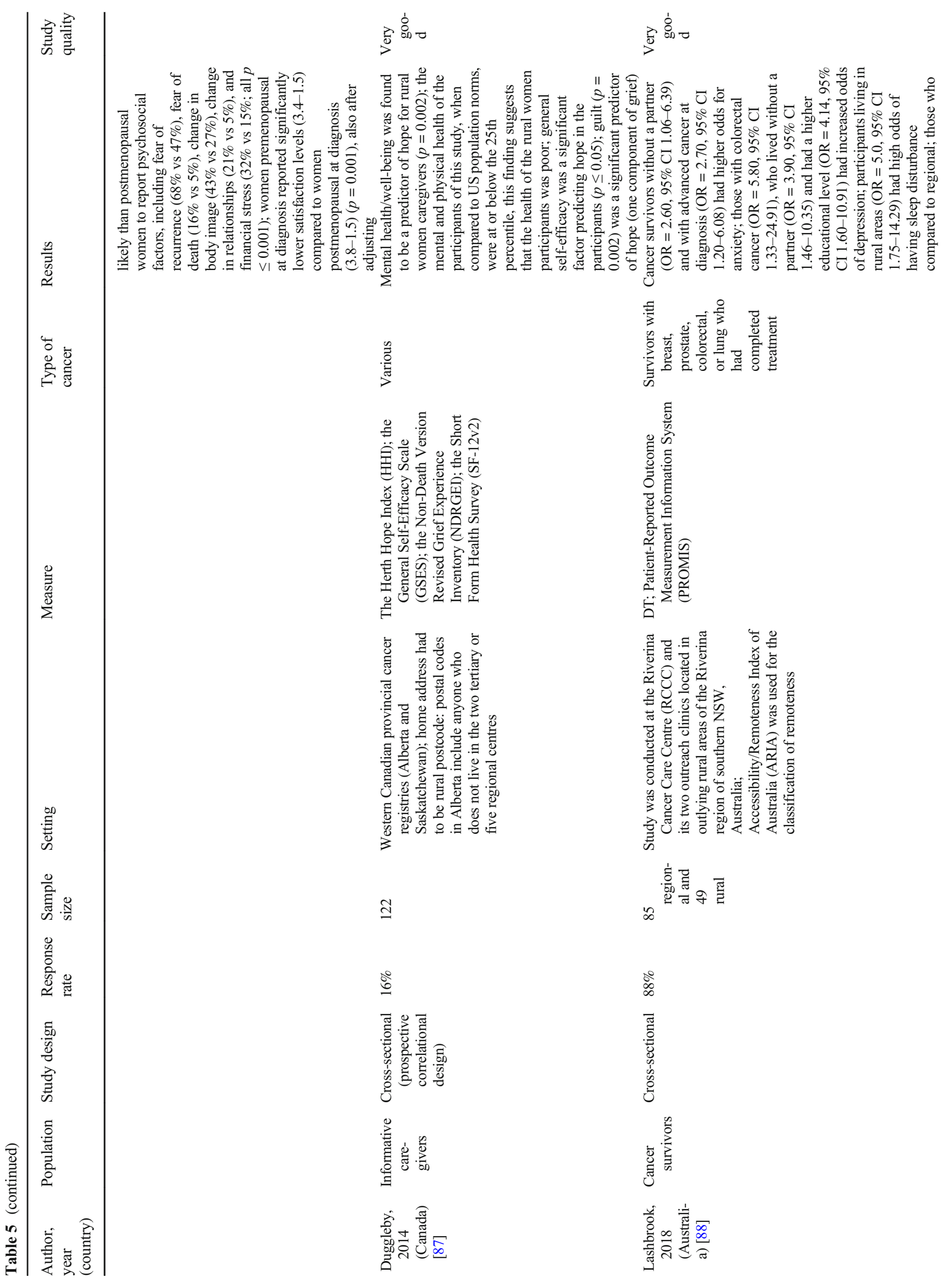




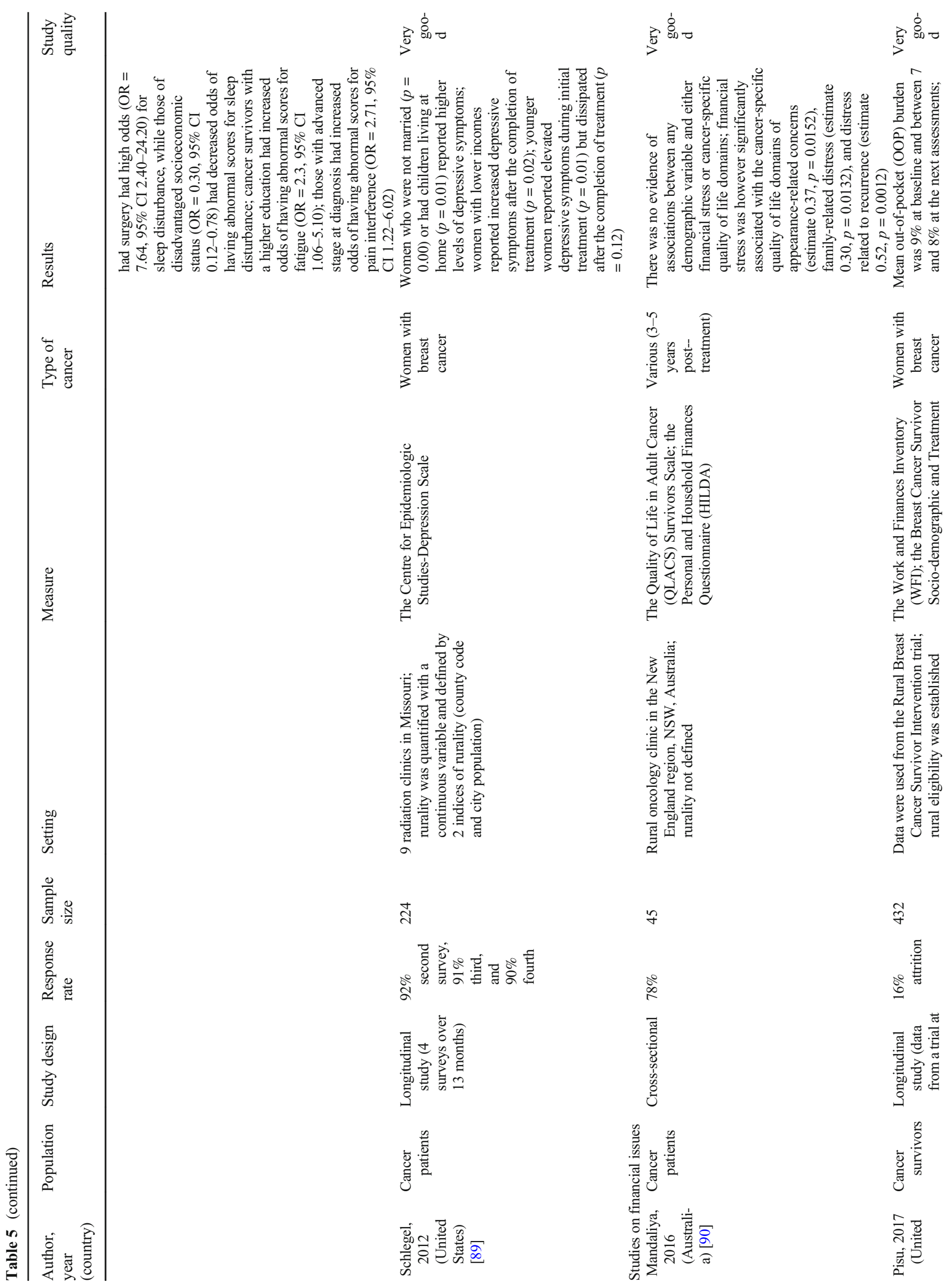




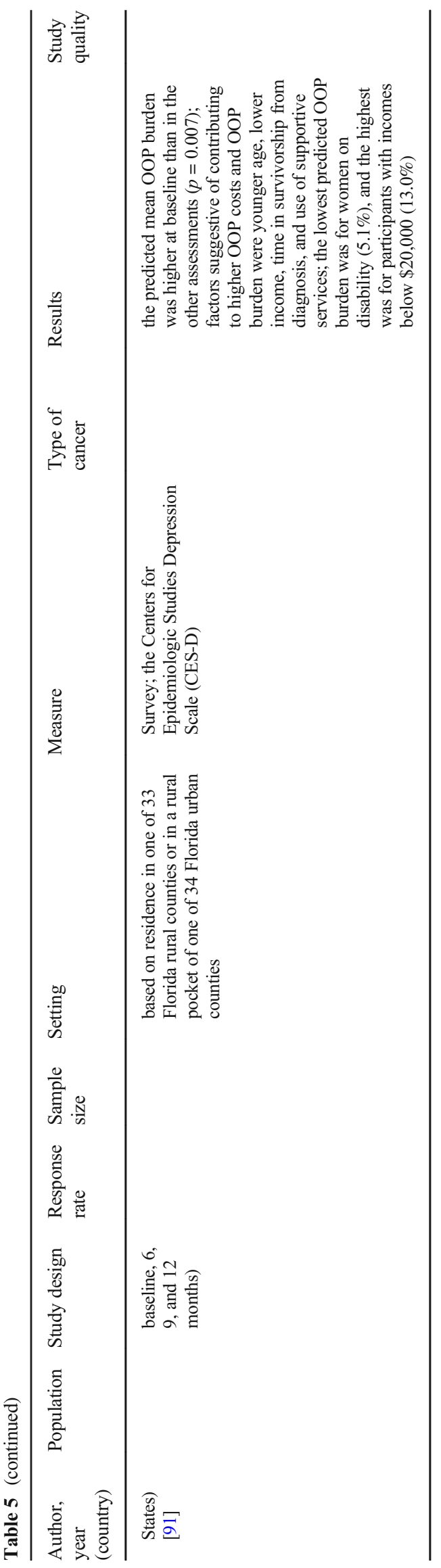

cancer, three each with colorectal and prostate cancer, and two each with lung and head and neck cancer. Of these 41 quantitative studies, 27 included both urban and rural cancer survivors.

There were four mixed methods studies, of which three were conducted in the US and one in Scotland. Two of these studies were conducted in people with breast cancer and two in a heterogenous cancer population. None of these four studies integrated the quantitative and qualitative data.

\section{Risk of bias within the studies}

Of the 20 qualitative studies, none were considered of poor methodological quality. Ten studies were considered to be of very good methodological quality and 10 considered good (Tables 2 and 3). Of the 41 quantitative studies, 33 studies were considered to be of very good methodological quality, five of good quality, and three poor (Tables 4 and 5). Most mixed methods studies were of good methodological quality, except for one study that was very good (Table 6).

\section{Results of studies}

Results of qualitative studies including both rural and urban survivors are presented below, followed by qualitative studies including only rural survivors, quantitative studies with rural and urban comparison groups, quantitative studies including only rural survivors, and mixed methods studies.

\section{Qualitative studies including both rural and urban survivors}

Seven qualitative studies with both rural and urban cancer groups [31-37], exploring respectively general needs and psychological morbidity, and financial issues and travel issues, were identified (Table 2). Compared with urban cancer survivors, more rural cancer survivors discussed having experienced a delay in their cancer diagnosis [32]. However, rural participants were more satisfied with their cancer care, even though they were aware that not all cancer care services were available where they lived. Rural African American cancer participants also talked more about using spirituality throughout their diagnosis and treatment than those who lived in urban areas [31, 33].

An Australian study on travel issues that included both rural and urban survivors [36] found that the experience of relocation was associated with psychosocial stress, due to a lack of support and loneliness but also because of concerns about the impact of separation on family members remaining at home. Another Australian study [37] found that lengthy travel, distance, lack of opportunity to take leave from work, and the additional costs of relocation and treatment all added to the stress of relocation. A third Australian study [35] found that visits by metropolitan haematologists to regional areas 


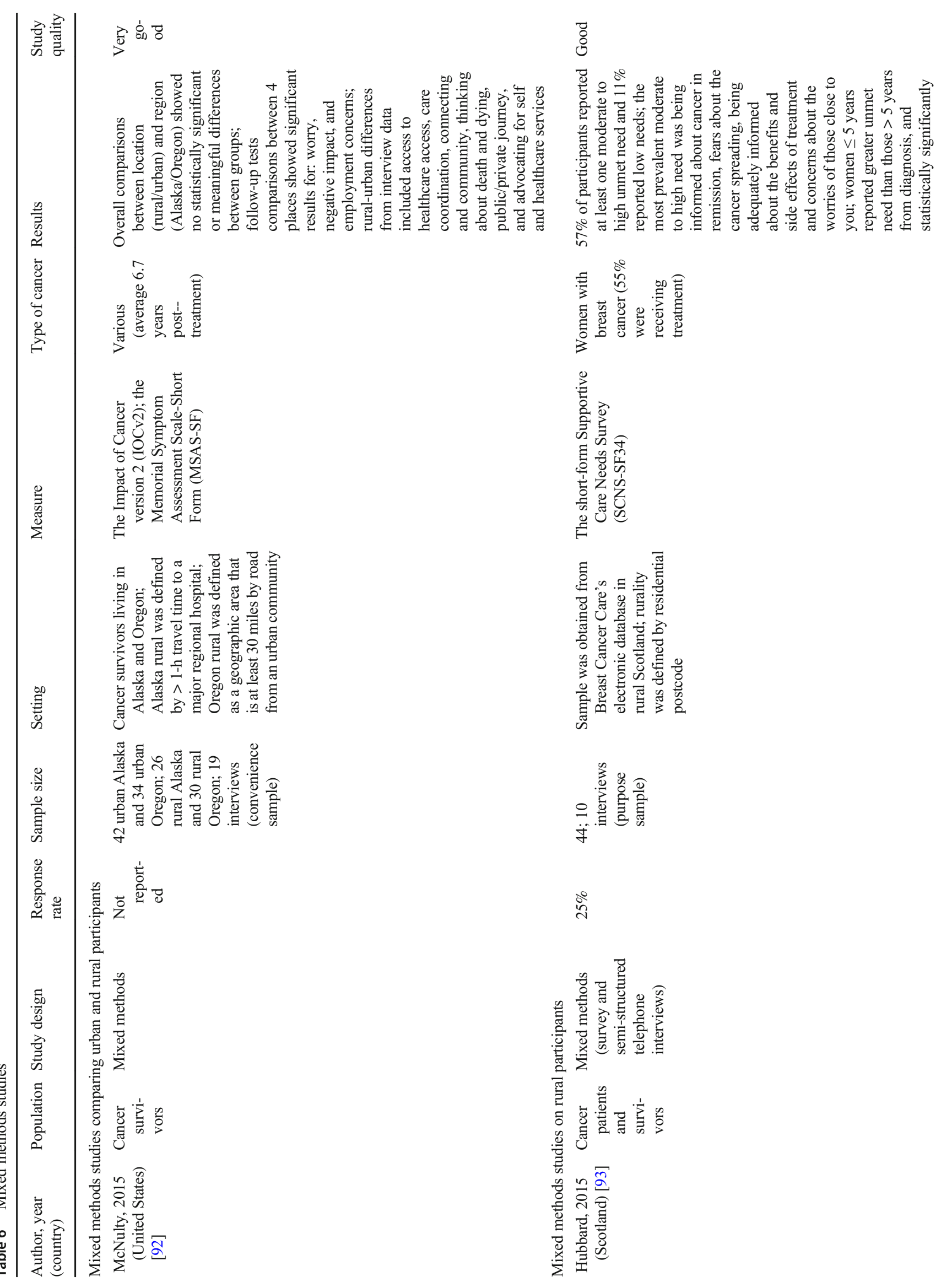




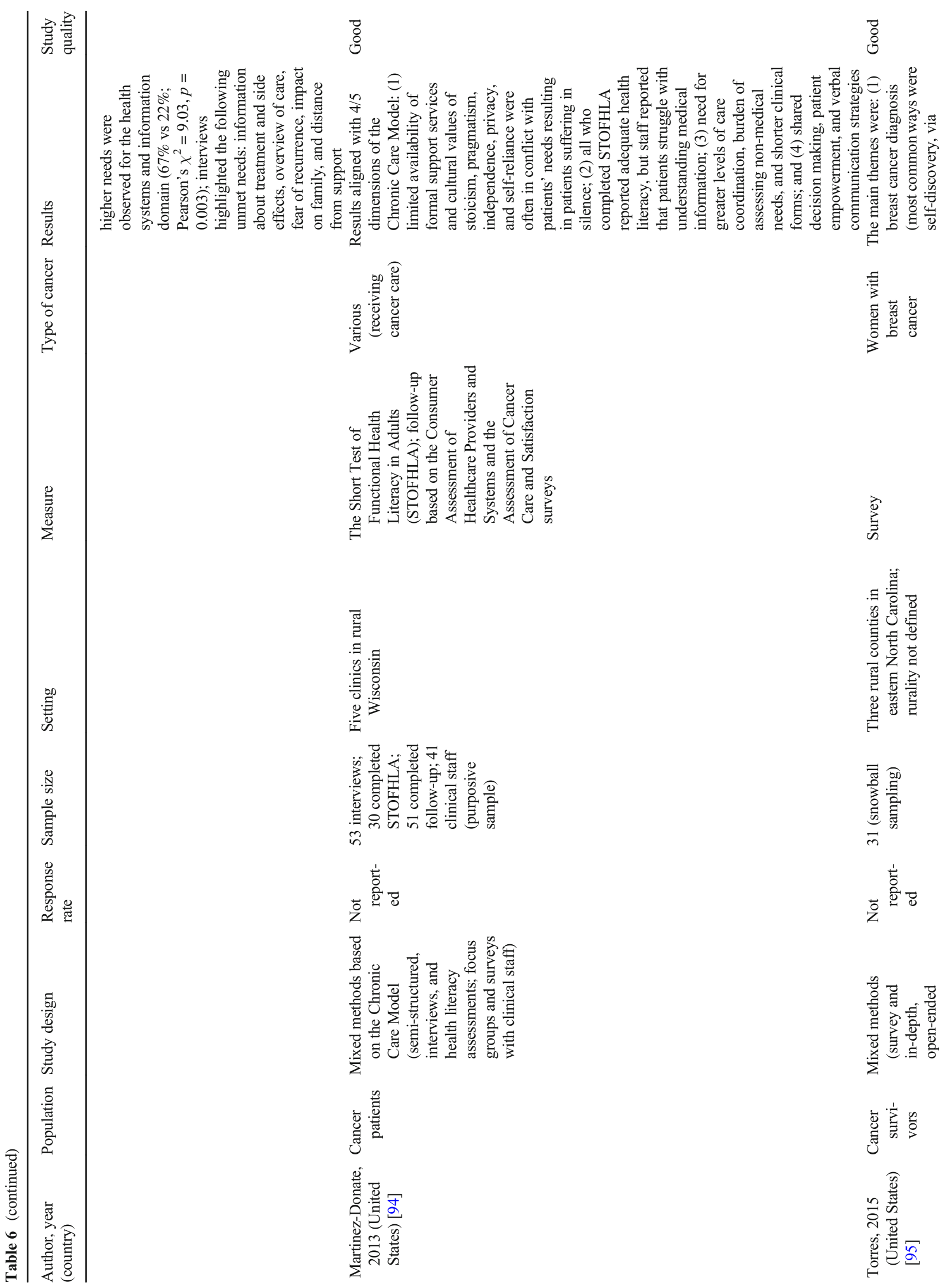


reduce stress associated with separation from family, the need for lengthy travel, and the financial cost of treatment. Furthermore, this study found that the opportunity to undergo part or all of treatment at regional hospitals is physically less demanding, more convenient and time saving, establishes bonds of trust and friendship with regional health professionals, lessens the emotional impact of diagnosis and treatment, and has financial benefits for patients.

\section{Qualitative studies including only rural survivors}

Thirteen qualitative studies including only rural cancer survivors were identified (Table 3) [38-50]. Two Australian studies $[38,39]$ found several issues in the provision of psychosocial care including access to appropriate psychosocial services (e.g., lack of information about services and concerns about stigma and dual relationships with service providers as friend/ physician) and lack of knowledge of the unique needs of rural cancer survivors by medical staff located in metropolitan treatment centres. However, those rural survivors who had accessed psychosocial support highly valued that support as it helped reduce uncertainty, fear and loneliness, and normalised patients' experiences [38]. Unmet needs included feeling let down by formal service provision, a sense of isolation, lack of referrals and follow-up care, inaccessibility of services due to distance, cost or wait times, and lack of appropriate care based on age, stage, or type of cancer [39]. Rural cancer patients suggested this could be improved by providing ruralspecific information on psychosocial care, improving communication between healthcare providers, and making psychosocial services a standard part of care [38]. Another Australian study [50] investigated rural cancer survivors' experience post-treatment in relation to QOL. This study found that a range of issues impacted the post-treatment QOL of rural cancer survivors, including fatigue and fear of cancer recurrence, and that these rural survivors lack information on how to access support to manage these issues. Participants highlighted several acceptable strategies to improve their QOL post-treatment, including nurse-led, telephone-based, or face-to-face interventions that include support with managing emotional challenges [50].

One Canadian study [44] looked at rural people with cancer in the palliative care setting. Four themes emerged: (1) community connectedness/isolation; (2) lack of accessibility to care; (3) communication and information issues; and (4) independence/dependence. Some of these findings resonated with a Norwegian study [43] that examined the lived experience of older rural persons receiving palliative treatment. This study found their participants struggled with having limited control, avoided becoming a burden, tried to live up to the expectations of being a 'good patient', and kept hope alive by dreaming and making plans. Several studies [40-42, 45-49] highlighted rural difficulties with support and isolation, and 
psychological issues such as a loss of control over the illness, anxiety, and a lack of knowledge. Some rural cancer patients stated that the information given was complex and in combination with condensed appointment schedules (to minimise travel) made the processing of information difficult. However, the support of family and home care services helped many transition through the physical and psychological demands that were encountered.

\section{Quantitative studies with rural and urban comparison groups}

Quantitative studies with an urban control group $(n=27)$ are presented in Table 4 [51-77]. Three addressed the use of formal and informal mental health resources, five examined financial and travel issues, one measured satisfaction with life, and the remainder explored the general needs, psychological morbidity, and QOL of cancer survivors and informal caregivers. Only two studies were longitudinal $[60,76]$.

Of the 19 studies exploring needs, psychological morbidity, and QOL, three (one US and two European) reported poorer outcomes for rural cancer survivors [63, 64, 68] and one (Australian) reported poorer outcomes for rural informal caregivers [56]. Five (one Australian, two US, and two European) reported poorer outcomes for urban cancer survivors $[57,59,61,62,65]$, one (Australian) found needs differed between groups [55], while nine (eight Australian and one US) concluded there were no meaningful differences between groups [54, 58, 60, 66, 67, 69-72]. Physical functioning, role functioning, and reported mental health outcomes were more likely to be worse in rural samples, whereas urban cancer survivors reported poorer social functioning and emotional QOL.

One US study of 113 heterogenous cancer survivors [51] found that rural cancer survivors reported significantly less favourable attitudes $(t(111)=2.05, p<0.05)$ and social norms $(t(111)=2.20, p<0.05)$ towards mental health resources than urban cancer survivors. Conversely, a German study of 534 colorectal cancer patients [52] showed that urban cancer patients were significantly less likely to talk with their doctor about their emotional state $(65 \%, p<0.01)$ and showed poorer knowledge $(60 \%, p<0.002)$ of cancer-specific mental health resources than rural cancer patients. There were no differences concerning distress, mental health outcomes, or acceptance of cancer-specific mental health resources between rural and urban cancer survivors (undergoing treatment and posttreatment) in the German sample [52].

A study conducted in Appalachian Kentucky (US) found that geographic location was significantly correlated with cancer-related financial distress among rural cancer survivors $(p=0.0013)$ [74]. Survivors who lived in regional or remote locations were 17 times more likely to report locational or financial barriers to accessing care compared to survivors living in metropolitan locations [73]. Another US study [75] found that the overall prevalence of financial burden was $20 \%$ higher among rural cancer survivors than urban cancer survivors. However, after adjusting for covariates, this finding became not statistically significant $(p=0.06)$. Another study [76] (Australian) found that regional or remote cancer patients (first year after diagnosis) were more likely to report travel burden compared to cancer patients living in major cities ( $\mathrm{OR}=18.9, p<0.001 ; \mathrm{OR}=135.7, p<0.001$, respectively). Similar findings were found for financial difficulties $(p<$ $0.05)$ [61], for which patients who travelled more than $2 \mathrm{~h}$ $(\mathrm{OR}=2.65, p=0.0178)$ or lived away for treatment $(\mathrm{OR}=$ $2.79, p=0.0152$ ) reported significantly greater financial difficulties than those who did not 6 months post-diagnosis [76].

One US study of 193 lung cancer survivors [65] examined differences between rural and urban cancer survivors in reports of positive outcomes, namely posttraumatic growth and benefit-finding of one's cancer experience. Although no significant differences were found for benefit-finding between the two groups, rural cancer survivors reported significant greater posttraumatic growth (effect size $(\mathrm{ES})=0.30 \mathrm{SD} ; p$ $=0.042$ ). Another study examined the satisfaction with life among women with breast cancer and found that rural women with breast cancer reported lower satisfaction with life than their urban counterparts $(p<0.001)$ [77].

\section{Quantitative studies including only rural survivors}

There were 14 quantitative studies including only rural cancer survivors [78-91], two on the use of formal and informal mental health resources, four on psychological needs and psychological morbidity, two on financial issues, and six on general needs and QOL. In total, four studies $[79,85,89,91]$ were longitudinal and only one study [87] was on informal caregivers (Table 5).

The single study on rural informal caregivers [87], with a sample of 122 participants, found that participants with higher hope had higher mental health scores $(\beta=0.266 ; p=0.002)$, lower perceptions of loss and grief $(\beta=-0.356 ; p=0.001)$, and were more confident in their ability to deal with difficult situations $(\beta=0.511 ; p=0.000)$. Other studies on psychological morbidity $[86,88,89]$ found that rural cancer survivors who lived without a partner $(\mathrm{OR}=3.90,95 \%$ CI $1.46-10.35)$ or had a higher educational level (OR $=4.14,95 \%$ CI 1.60 10.91) had increased odds of mild to severe levels of depression (i.e., score of $\geq 55$ ) [88]. One US study in rural women with breast cancer found that premenopausal women were more likely to experience depression at the time of treatment compared to postmenopausal women (39\% versus $23 \%$, respectively; $p<0.001$ ) [86]. This study also found that the most common concerns among all rural women with breast cancer (i.e., percentage of women who reported experiencing psychosocial factors) were fear of recurrence $(52 \%)$, diminished 
physical strength (39\%), change in body image (31\%), and financial stress (19\%) [86].

Four longitudinal studies $[79,85,89,91]$ reported findings on several topics. One Australian study [79] found that rural cancer patients with a more positive attitude towards help seeking were more likely to have utilised a support service 6 months following study commencement $(\mathrm{OR}=$ $1.69, p<0.05)$. One US study [91] found that the out-ofpocket (OOP) burden (i.e., OOP costs as a percentage of income) significantly declined over time for rural cancer survivors $(p=0.007)$; the predicted mean OOP burden was $9.8 \%$ at baseline, and between 7 and $8 \%$ at follow-up. Factors suggestive of contributing to higher OOP burden for rural cancer survivors included younger age, lower income, time in survivorship from diagnosis, and use of supportive services [91]. Another rural US study [89] found a decrease in depressive symptoms in the first 3 months after the start of treatment but an increase 5 months thereafter. This trend was observed due to the decrease in psychological distress immediately after completion of active treatment but increase thereafter due to the fear of recurrence. Lastly, one longitudinal study [85], on the needs and QOL of men with prostate cancer in rural Georgia, found that self-reported physical QOL (coefficient $=-5.8, p<0.0001$ ) and emotional QOL (coefficient $=-5.7, p<0.0001$ ) declined significantly after treatment.

A rural-focussed Australian study on financial issues found that financial stress was significantly associated with the cancer-specific QOL domains of appearance-related concerns ( $\mathrm{ES}=0.37, p=0.015)$, family-related distress $(\mathrm{ES}=0.30, p=$ 0.013 ), and distress-related to recurrence ( $\mathrm{ES}=0.52, p=$ 0.001 ) [90]. One Australian study on service use [78] found that despite most (82\%) of the rural men being aware of a formal service offering psychosocial support, only $49 \%$ of the rural men used such a service. This is contrary to another rural-focussed Australian study [79] that found only 14\% of participants reported having used a psychosocial support service.

The remainder of studies [80-85] were on the general needs and QOL of rural people affected by cancer, for which some also reported data on psychological morbidity and compared rural cancer patients with the general population, however excluded urban cancer groups. These studies found that $25 \%$ of the rural cancer survivors reported high/very high emotional health needs, $38 \%$ reported fatigue, and $28 \%$ reported depression. QOL scores seemed to be lower in rural cancer survivors compared to the general population. However, rural cancer patients reported better social/family well-being compared to the general population. Finally, rural cancer patients reported that support groups were very helpful, though some participants reported that they did not attend because of a lack of knowledge about current support groups and times.

\section{Mixed methods studies}

There were four studies that used a mixed methods approach (Table 6) [92-95]. One study, comparing rural and urban cancer survivors, found no statistically meaningful differences between groups in the quantitative analysis [92]. However, the qualitative analysis revealed that rural cancer survivors had more challenges than urban cancer survivors including access to healthcare, care coordination, and the very public journey of their survivorship due to the close-knit nature of their communities. The other three studies among rural cancer survivors showed that health systems and information, psychological needs, and quality of care were the most frequently reported domains of unmet needs [93-95]. The interviews from one study [93] also highlighted the following unmet rural needs: information about treatment and side effects, overview of care, fear of recurrence, impact on family, and distance from support.

\section{Discussion}

\section{Summary of evidence}

\section{Main findings}

This systematic review examined the research conducted over the last 10 years on the psychosocial well-being and supportive care needs of cancer patients and survivors living in urban and rural/regional areas. The 65 studies included in this review, of which most studies were conducted in Australia (28/ $65 ; 43 \%)$ followed by the US $(24 / 65 ; 37 \%)$, demonstrated that among the studies that found a difference, rural cancer survivors were more likely to report worse outcomes in physical functioning, role functioning, and reported mental health, whereas urban cancer survivors were more likely to report poorer outcomes in social functioning and emotional QOL. However, most studies that compared rural and urban cancer survivors found no differences between the two populations with regard to psychosocial well-being and QOL. This review also found that rural cancer survivors were more likely to report unmet needs relating to financial and travel issues and experience more difficulties with accessing care compared to urban cancer survivors. This highlights that rural and urban cancer survivors have different psychological needs and concerns, and rural cancer survivors have some additional unmet needs related to rurality that require careful assessment and management

\section{Context within the 2011 systematic review}

Over the last 10 years, research on the psychosocial wellbeing and supportive care needs of rural and urban cancer 
survivors has increased. The previous systematic review on the same topic identified 37 studies that were published before August 2010. Our review included 65 studies published between August 2010 and May 2021. Compared to the 2011 review, more studies included in this review were conducted in people with heterogenous cancers (30 versus 11 ), and included a control group of urban cancer survivors (27 versus 11 ) or used a general population control group (3 versus 1 ). Moreover, the quality of studies seems to have improved over the last 10 years as the studies included in this review had better reporting of design ( $68 \%$ versus $54 \%$ ), and more often defined rurality or used a validated measurement tool, compared to the 2011 systematic review.

This review identified three studies $[64,68,71]$ that included rural and urban general population control groups, and directly compared rural and urban cancer populations. These studies found that significant differences existed in health outcomes between rural and urban cancer survivors and healthy controls (one study was matched on age [68], and one study was matched on age, gender, and country of residence [64]). More specifically, cancer survivors in general reported poorer self-rated health compared to healthy controls, for which rural cancer survivors reported slightly poorer outcomes than urban cancer survivors. However, after adjusting for sociodemographic factors, rural and urban cancer survivors reported similar outcomes, nonetheless poorer than healthy controls. Conversely, the 2011 review that included only one population-based control study found that the ageadjusted QOL was similar among all groups. However, while our review identified three population-based control studies that included a heterogenous or lung cancer population, the 2011 review identified a single population-based control study that included only breast cancer survivors, who in general report better QOL outcomes compared to lung cancer survivors for example, and have better overall survival rates [96].

While 9 quantitative studies with an urban control group in this review showed no evidence of meaningful differences between rural and urban cancer survivors $[54,58,60,66$, 67, 69-72], five studies concluded that urban cancer survivors reported poorer psychosocial outcomes than rural cancer survivors $[57,59,61,62,65]$ and three studies found that rural cancer survivors reported poorer psychosocial outcomes than their urban counterparts $[63,64,68]$. These findings differ from the 2011 review on this topic, which found that rural cancer survivors generally reported worse outcomes than urban cancer survivors. Recent research suggests that rural cancer survivors may have greater protective factors against poorer emotional health, including active coping styles, positive reinterpretation [16], and the belief that a person's health is decided by powerful others [97], that urban cancer survivors may be lacking. Studies have also shown that people living in rural areas not only tend to be more stoic about their health, which could result in under-reporting of distress, but also differ in their expectations of health services than people living in urban areas $[98,99]$. In addition, rural cancer survivors report higher levels of community trust, which may buffer the impact of a lack of professional psychosocial support services in rural areas [69]. This may explain rural cancer survivors reporting fewer unmet emotional needs than urban cancer survivors. Further, it is also possible that the introduction of numerous regional cancer centres in the last 10 years in Australia, where many of these studies were conducted, has helped reduce the psychosocial toll of a cancer diagnosis for rural Australians. Moreover, the increase use in technology (e.g., telehealth) and digital healthcare may also have helped to overcome the tyranny of distance and led to improvements.

The majority of studies focussed on a heterogenous group of cancer survivors $(30 / 65 ; 46 \%)$, followed by breast cancer survivors $(13 / 65 ; 20 \%)$ and haematological cancer patients $(8 / 65 ; 12 \%)$.

In the qualitative studies with urban comparison groups, findings were similar to the 2011 review regarding unmet needs and travel issues. In both reviews, rural cancer survivors reported more frequent episodes of delayed diagnosis compared to urban cancer survivors [32]. Other challenges that were similar to the 2011 review included difficulties with access to healthcare and care coordination/navigation, for which rural cancer survivors reported more challenges than urban cancer survivors [92]. Furthermore, in both systematic reviews, the qualitative studies confirmed the findings on travel issues in quantitative studies [35-37]. Both reviews found that travelling caused additional stress, can put pressure on family relationships, and in general posed difficulties to patients. This was also found in qualitative studies without an urban control group in both reviews, highlighting that rural cancer survivors and families report difficulties with support and isolation, psychological issues such as a loss of control over the illness, anxiety, and a lack of knowledge, and access to mental health services. The current review also highlighted an additional finding that a lack of opportunity to take leave from work may mean that some rural cancer survivors cannot undergo treatment [37]. This may be related to the greater proportion of people who are self-employed in rural versus urban areas [100]. However, although these challenges are still apparent in rural cancer survivors, more research is needed that investigates whether these challenges have improved with the increased use and quality of telehealth and digital healthcare over time.

In total, six longitudinal studies (four without a control group) were identified in this study. The longitudinal studies with a control group $[60,76]$ found that rural cancer survivors reported lower QOL (6 months post-treatment) and greater travel burden (12 months post-diagnosis) compared with urban cancer survivors over time. The studies without a control group [79, 85, 89, 91] found that the out-of-pocket burden and QOL declined over time (1-3 years post-diagnosis). However, 
levels of depression increased 12 months post-diagnosis after an initial decline 3 months after the start of treatment. The 2011 review also found that the health system and information needs of rural cancer patients decreased over time. These findings suggest that needs may change along the cancer survivorship continuum. For instance, post-diagnosis needs might revolve around providing information and support, whereas post-treatment needs focus more around the practical issues of being able to perform activities of daily living.

\section{Limitations}

While this systematic review provides updated information on what is known about levels of psychosocial morbidity and the needs of rural people with cancer and their informal caregivers, the results should be interpreted with the following limitations in mind. First, this review has brought together studies that were conducted in multiple developed countries that used different definitions for rurality, such as the ARIA (Australia) and the Rural-Urban Continuum (RUC; US). Additionally, studies included in this review used different methodological approaches and different data sources. Conducting a separate qualitative and quantitative review may have had merit, but we wanted to follow the successful approach employed in the previous review. As these studies were very heterogeneous, no meta-analysis was conducted, and the findings of this review are conceptual rather than statistical. As most studies included in this review used a cross-sectional design, it was impossible to explore causality. Further, all data reported on in the studies contained in this review were collected prior to the COVID-19 epidemic, which may have led to improvements in remote access to support services, with particular benefits for rural populations. Second, the search strategy was restricted to Englishlanguage publications, which made it impossible to comment on the experiences of rural cancer survivors living in nonEnglish-speaking countries. Lastly, as the scope of this review was psychosocial in nature, physical morbidity and medical outcomes or survival rates were excluded. As these outcomes are closely related to a cancer survivor's psychosocial wellbeing and needs, there may have been merit in broadening the scope of the review to include them. However, this would have limited our ability to make comparisons with the findings from the previous review.

\section{Conclusions}

Over the last 10 years, the number of studies on the topic of psychosocial morbidity and unmet needs in rural cancer survivors has almost doubled. While 37 studies were identified in the 2011 review, this study identified 65 new studies published after July 2010. Many (9/19) quantitative studies with an urban control group did not report any meaningful differences between rural and urban cancer survivors with regard to psychosocial morbidity or general unmet needs. There were slightly more quantitative studies with control groups that reported worse outcomes in urban cancer survivors $(5 / 19)$ than rural cancer survivors (3/19), for which urban cancer survivors reported worse social and emotional functioning and rural cancer survivors reported worse physical functioning, role functioning, and reported mental health outcomes compared to their counterparts. Nonetheless, many needs were still unmet in both populations, and people with cancer living in rural areas were found to face different, additional financial and travel issues, and experience difficulties accessing care. These uniquely rural psychosocial challenges need careful assessment and management by health professionals, if equality in treatment outcomes between rural and urban populations is to be achieved. Further longitudinal research is also warranted that includes both rural and urban cancer groups and includes population-based control groups, to establish whether differences in psychosocial outcomes between rural and urban survivors are due to general geographic or cancerspecific factors. This will help inform the development of future intervention trials that seek to test new strategies to address key issues, in the populations who need them most.

Availability of data and material We have control of all data and agree to allow the journal to review our data if required.

Author contribution Shannen R. van der Kruk: conceptualisation, data curation, formal analysis, methodology, project administration, writing — original draft

Phyllis Butow: conceptualisation, methodology, supervision, writing — review and editing

Ilse Mesters: methodology, formal analysis, supervision, writing review and editing

Terry Boyle: methodology, supervision, writing — review and editing Ian Olver: methodology, formal analysis, writing — review and editing

Kate White: formal analysis, writing — review and editing

Sabe Sabesan: formal analysis, writing — review and editing

Rob Zielinski: formal analysis, writing — review and editing

Bryan A. Chan: formal analysis, writing — review and editing

Kristiaan Spronk: data curation, formal analysis, writing — review and editing

Peter Grimison: writing — review and editing

Craig Underhill: writing — review and editing

Laura Kirsten: writing — review and editing

Kate M. Gunn: conceptualisation, formal analysis, methodology, project administration, resources, supervision, writing — review and editing

\section{Declarations}

Ethics approval Not applicable.

Consent to participate Not applicable.

Consent for publication Not applicable. 
Conflict of interest The authors declare no competing interests.

\section{References}

1. Hewitt M, Greenfield S, Stovall E (2005) From cancer patient to cancer survivor: lost in transition. National Academies Press,

2. Australian Institute of Health and Welfare (2020) Cancer data in Australia. AIHW. https://www.aihw.gov.au/reports/cancer/ cancer-data-in-australia. Accessed 13 October 2020

3. Alfano CM, Jefford M, Maher J, Birken SA, Mayer DK (2019) Building personalized cancer follow-up care pathways in the United States: lessons learned from implementation in England, Northern Ireland, and Australia. Am Soc Clin Oncol Educl Book 39:625-639

4. Wait S, Han D, Muthu V, Oliver K, Chrostowski S, Florindi F, de Lorenzo F, Gandouet B, Spurrier G, Ryll B (2017) Towards sustainable cancer care: reducing inefficiencies, improving outcomes - a policy report from the All Can initiative. J Cancer Policy 13:47-64

5. Gysels M, Higginson I, Rajasekaran M, Davies E, Harding R (2004) Improving supportive and palliative care for adults with cancer: research evidence. Natl Instit Health Clin Excell. https:// www.nice.org.uk/guidance/csg4. Accessed 2 June 2020

6. Boyes AW, Girgis A, D'Este C, Zucca AC (2012) Prevalence and correlates of cancer survivors' supportive care needs 6 months after diagnosis: a population-based cross-sectional study. BMC Cancer 12(1): 150

7. Recklitis CJ, Syrjala KL (2017) Provision of integrated psychosocial services for cancer survivors post-treatment. Lancet Oncol 18(1):e39-e50

8. Blinman PL, Grimison P, Barton MB, Crossing S, Walpole ET, Wong N, Francis K, Koczwara B (2012) The shortage of medical oncologists: the Australian Medical Oncologist Workforce Study. Med J Aust 196(1):58-61

9. Beesley V, Eakin E, Steginga S, Aitken J, Dunn J, Battistutta D (2008) Unmet needs of gynaecological cancer survivors: implications for developing community support services. Psycho-Oncol : J Psychol Soc Behav Dimens Cancer 17(4):392-400

10. Harrison JD, Young JM, Price MA, Butow PN, Solomon MJ (2009) What are the unmet supportive care needs of people with cancer? A systematic review. Support Care Cancer 17(8):11171128

11. Diaz A, Whop LJ, Valery PC, Moore SP, Cunningham J, Garvey G, Condon JR (2015) Cancer outcomes for Aboriginal and Torres Strait Islander Australians in rural and remote areas. Aust J Rural Health 23(1):4-18. https://doi.org/10.1111/ajr.12169

12. Jong KE, Smith DP, Yu XQ, O'Connell DL, Goldstein D, Armstrong BK (2004) Remoteness of residence and survival from cancer in New South Wales. Med J Aust 180(12):618-622

13. Baade PD, Dasgupta P, Aitken JF, Turrell G (2011) Distance to the closest radiotherapy facility and survival after a diagnosis of rectal cancer in Queensland. Med J Aust 195(6):350-354

14. Carriere R, Adam R, Fielding S, Barlas R, Ong Y, Murchie P (2018) Rural dwellers are less likely to survive cancer - an international review and meta-analysis. Health Place 53:219-227

15. Angell KL, Kreshka MA, Mc Coy R, Donnelly P, Turner-Cobb JM, Graddy K, Kraemer HC, Koopman C (2003) Psychosocial intervention for rural women with breast cancer: the Sierra Stanford partnership. J Gen Intern Med 18(7):499-507

16. Wilson SE, Andersen MR, Meischke H (2000) Meeting the needs of rural breast cancer survivors: what still needs to be done? J Womens Health Gend Based Med 9(6):667-677
17. Zucca A, Boyes A, Girgis A, Hall A (2009) Travel all over the countryside: travelling for cancer treatment in NSW and Victoria. Asia-Pac J Clin Oncol 5

18. Shugarman LR, Sorbero ME, Tian H, Jain AK, Ashwood JS (2008) An exploration of urban and rural differences in lung cancer survival among Medicare beneficiaries. Am J Public Health 98(7):1280-1287

19. Probst JC, Laditka SB, Wang J-Y, Johnson AO (2007) Effects of residence and race on burden of travel for care: cross sectional analysis of the 2001 US National Household Travel Survey. BMC Health Serv Res 7(1):40

20. Charlton M, Schlichting J, Chioreso C, Ward M, Vikas P (2015) Challenges of rural cancer care in the United States. Oncology 29(9):633-640

21. Australian Institute of Health Welfare (2019) Rural \& Remote Health. AIHW. https://www.aihw.gov.au/reports/rural-remoteaustralians/rural-remote-health. Accessed 16 March 2020

22. Meilleur A, Subramanian S, Plascak JJ, Fisher JL, Paskett ED, Lamont EB (2013) Rural residence and cancer outcomes in the United States: issues and challenges. Cancer Epidemiol Prev Biomarkers 22(10): 1657-1667

23. Butow PN, Phillips F, Schweder J, White K, Underhill C, Goldstein D (2012) Psychosocial well-being and supportive care needs of cancer patients living in urban and rural/regional areas: a systematic review. Support Care Cancer 20(1):1-22

24. Yu XQ, Luo Q, Kahn C, O'Connell DL, Houssami N (2015) Temporal trends show improved breast cancer survival in Australia but widening urban-rural differences. Breast 24(4): 524-527. https://doi.org/10.1016/j.breast.2015.03.006

25. Kennedy AE, Vanderpool RC, Croyle RT, Srinivasan S (2018) An overview of the National Cancer Institute's initiatives to accelerate rural cancer control research. Cancer Epidemiol Prev Biomarkers 27(11):1240-1244

26. Moher D, Liberati A, Tetzlaff J, Altman DG (2010) Preferred reporting items for systematic reviews and meta-analyses: the PRISMA statement. Int J Surg 8(5):336-341

27. Australian Government (2001) Measuring remoteness: accessibility/remoteness index of Australia (ARIA). Department of Health and Aged Care. https://www1.health.gov.au/internet/ main/publishing.nsf/Content/health-historicpubs-hfsoccocpanew14a.htm. Accessed 2 March 2020

28. United Nations Development Programme (2019) Human development report 2019: beyond income, beyond averages, beyond today: inequalities in human development in the 21 st century. https://www.un-ilibrary.org/content/publication/838f78fd-en. Accessed 8 April 2020

29. Peters MD, Godfrey CM, McInerney P, Soares CB, Khalil H, Parker D (2015) The Joanna Briggs Institute reviewers' manual 2015: methodology for JBI scoping reviews.

30. Pluye P, Robert E, Cargo M, Bartlett G, O'cathain A, Griffiths F, Boardman F, Gagnon M-P, Rousseau M (2011) Proposal: a mixed methods appraisal tool for systematic mixed studies reviews. Montréal: McGill University 2:1-8

31. Jones RA, Wenzel J, Hinton I, Cary M, Jones NR, Krumm S, Ford JG (2011) Exploring cancer support needs for older AfricanAmerican men with prostate cancer. Support Care Cancer 19(9): 1411-1419

32. Miedema B, Easley JK, Robinson LM (2013) Comparing urban and rural young adult cancer survivors' experiences: a qualitative study. Rural Remote Health 13(2):2324

33. Wenzel J, Jones RA, Klimmek R, Krumm S, Darrell LP, Song D, Stearns V, Ford JG (2012) Cancer support and resource needs among African American older adults. Clin J Oncol Nurs 16(4): 372-377

34. Galica J, Giroux J, Francis JA, Maheu C (2020) Coping with fear of cancer recurrence among ovarian cancer survivors living in 
small urban and rural settings: a qualitative descriptive study. Eur J Oncol Nurs 44:101705

35. McGrath P (2015) Overcoming the distance barrier in relation to treatment for haematology patients: Queensland findings. Aust Health Rev 39(3):344-350

36. McGrath $P$ (2015) Findings on family issues during relocation for hematology care. Oncol Nurs Forum 42(3):E250-E256

37. McGrath P (2015) 'You never leave work when you live on a cattle property': special problems for rural property owners who have to relocate for specialist treatment. Aust J Rural Health 23(5): 286-290

38. Gunn K, Turnbull D, McWha JL, Davies M, Olver I (2013) Psychosocial service use: a qualitative exploration from the perspective of rural Australian cancer patients. Support Care Cancer 21(9):2547-2555

39. Pascal J, Johnson N, Dickson-Swift V, Kenny A (2015) Returning home: psychosocial care during the re-entry phase of cancer survivorship in rural Australia. Eur J Cancer Care (Engl) 24(1):39-49

40. Adams N, Gisiger-Camata S, Hardy CM, Thomas TF, Jukkala A, Meneses K (2017) Evaluating survivorship experiences and needs among rural African American breast cancer survivors. J Cancer Educ 32(2):264-271

41. Allen KR, Roberto KA (2014) Older women in Appalachia: experiences with gynecological cancer. The Gerontologist 54(6): 1024-1034

42. Coyne E, Frommolt V, Salehi A (2019) The experience and challenges of rural persons with cancer and their families. Collegian 26(6):609-614

43. Devik SA, Enmarker I, Wiik GB, Hellzen O (2013) Meanings of being old, living on one's own and suffering from incurable cancer in rural Norway. Eur J Oncol Nurs 17(6):781-787

44. Duggleby W, Penz K, Leipert B, Wilson D, Goodridge D, Williams A (2011) 'I am part of the community but...'The changing context of rural living for persons with advanced cancer and their families. Rural Remote Health 11(3):1733

45. Garrard ED, Fennell KM, Wilson C (2017) 'We're completely back to normal, but I'd say it's a new normal': a qualitative exploration of adaptive functioning in rural families following a parental cancer diagnosis. Support Care Cancer 25(11):35613568

46. Grimison P, Phillips F, Butow P, White K, Yip D, Sardelic F, Underhill C, Tse R, Simes R, Turley K, Raymond C, Goldstein D (2013) Are visiting oncologists enough? A qualitative study of the needs of Australian rural and regional cancer patients, carers and health professionals. Asia Pac J Clin Oncol 9(3):226-238

47. Loughery J, Woodgate RL (2019) Supportive care experiences of rural women living with breast cancer: an interpretive descriptive qualitative study. Can Oncol Nurs J 29(3):170-176

48. Sawin EM (2010) 'My husband would not help me, so I was driving over there': older rural women experiencing breast cancer with a nonsupportive intimate partner. Rural Remote Health 10(4):1-13

49. Wagland K, Levesque JV, Connors J (2015) Disease isolation: the challenges faced by mothers living with multiple myeloma in rural and regional Australia. Eur J Oncol Nurs 19(2):148-153

50. Gunn KM, Olver I, Skrabal Ross X, Harrison N, Livingston PM, Wilson C (2021) Improving survivors' quality of life post-treatment: the perspectives of rural australian cancer survivors and their carers. Cancers 13(7):1600

51. Andrykowski MA, Burris JL (2010) Use of formal and informal mental health resources by cancer survivors: differences between rural and nonrural survivors and a preliminary test of the theory of planned behavior. Psycho-Oncology 19(11):1148-1155

52. Beraldi A, Kukk E, Nest A, Schubert-Fritschle G, Engel J, Heusner P, Herschbach P (2015) Use of cancer-specific mental health resources - is there an urban-rural divide? Support Care Cancer 23(5):1285-1294

53. Corboy D, McLaren S, Jenkins M, McDonald J (2014) The relationship between geographic remoteness and intentions to use a telephone support service among Australian men following radical prostatectomy. Psychooncology 23(11):1259-1266

54. Ahern T, Gardner A, Courtney M (2015) Geographical comparisons of information and support needs of Australian women following the primary treatment of breast cancer: a 10-year replication study. Health Expect 18(6):2678-2692

55. Ahern T, Gardner A, Courtney M (2016) Exploring patient support by breast care nurses and geographical residence as moderators of the unmet needs and self-efficacy of Australian women with breast cancer: results from a cross-sectional, nationwide survey. Eur J Oncol Nurs 23:72-80

56. Lynagh MC, Williamson A, Bradstock K, Campbell S, Carey M, Paul C, Tzelepis F, Sanson-Fisher R (2018) A national study of the unmet needs of support persons of haematological cancer survivors in rural and urban areas of Australia. Support Care Cancer 26(6): 1967-1977

57. Tzelepis F, Paul CL, Sanson-Fisher RW, Campbell HS, Bradstock K, Carey ML, Williamson A (2018) Unmet supportive care needs of haematological cancer survivors: rural versus urban residents. Ann Hematol 97(7):1283-1292

58. White KJ, Roydhouse JK, D'Abrew NK, Katris P, O'Connor M, Emery L (2011) Unmet psychological and practical needs of patients with cancer in rural and remote areas of Western Australia. Rural Remote Health 11(3):1784

59. Cahir C, Thomas AA, Dombrowski SU, Bennett K, Sharp L (2017) Urban-rural variations in quality-of-life in breast cancer survivors prescribed endocrine therapy. Int J Environ Res Public Health 14(4):07

60. Pateman KA, Cockburn NL, Batstone MD, Ford PJ (2018) Quality of life of head and neck cancer patients in urban and regional areas: an Australian perspective. Aust J Rural Health 26(3):157-164

61. Pedro LW, Schmiege SJ (2014) Rural living as context: a study of disparities in long-term cancer survivors. Oncol Nurs Forum 41(3):E211-E219

62. Thomas AA, Timmons A, Molcho M, Pearce A, Gallagher P, Butow P, O'Sullivan E, Gooberman-Hill R, O'Neill C, Sharp L (2014) Quality of life in urban and rural settings: a study of head and neck cancer survivors. Oral Oncol 50(7):676-682

63. Thomas AA, Gallagher P, O'Ceilleachair A, Pearce A, Sharp L, Molcho M (2015) Distance from treating hospital and colorectal cancer survivors' quality of life: a gendered analysis. Support Care Cancer 23(3):741-751

64. Andrykowski MA, Steffens RF, Bush HM, Tucker TC (2014) Disparities in mental health outcomes among lung cancer survivors associated with ruralness of residence. Psycho-Oncology 23(4):428-436

65. Andrykowski MA, Steffens RF, Bush HM, Tucker TC (2017) Posttraumatic growth and benefit-finding in lung cancer survivors: the benefit of rural residence? J Health Psychol 22(7):896-905

66. Carey M, Sanson-Fisher R, Paul C, Bradstock K, Williamson A, Campbell HS (2017) Psychological morbidity among Australian rural and urban support persons of haematological cancer survivors: results of a national study. Psychooncology 26(11):19521958

67. Corboy D, Meier J, McLaren S (2019) Self-reliance and stoicism as predictors of distress following radical prostatectomy in the context of place of residence. Psychol Men Masculinities 20(4): 637-646

68. Grov EK, Fossa SD, Dahl AA (2011) Short-term and long-term elderly cancer survivors: a population-based comparative and 
controlled study of morbidity, psychosocial situation, and lifestyle. Eur J Oncol Nurs 15(3):213-220

69. Gunn KM, Berry NM, Meng X, Wilson CJ, Dollman J, Woodman RJ, Clark RA, Koczwara B (2020) Differences in the health, mental health and health-promoting behaviours of rural versus urban cancer survivors in Australia. Support Care Cancer 28(2):633-643

70. Hall AE, Sanson-Fisher RW, Carey ML, Paul C, Williamson A, Bradstock K, Campbell HS (2016) Prevalence and associates of psychological distress in haematological cancer survivors. Support Care Cancer 24(10):4413-4422

71. Schootman M, Homan S, Weaver KE, Jeffe DB, Yun S (2013) The health and welfare of rural and urban cancer survivors in Missouri. Prev Chronic Dis 10:E152

72. Watts KJ, Good LH, McKiernan S, Miller L, O'Connor M, Kane R, Kruger DJ, Adams BR, Musiello T (2016) "Undressing" distress among cancer patients living in urban, regional, and remote locations in Western Australia. Support Care Cancer 24(5):19631973

73. Paul CL, Hall AE, Carey ML, Cameron EC, Clinton-McHarg T (2013) Access to care and impacts of cancer on daily life: do they differ for metropolitan versus regional hematological cancer survivors? J Rural Health 29(Suppl 1):s43-s50

74. Vanderpool RC, Chen Q, Johnson MF, Lei F, Stradtman LR, Huang B (2020) Financial distress among cancer survivors in Appalachian Kentucky. Cancer Rep 3(2):e1221

75. Zahnd WE, Davis MM, Rotter JS, Vanderpool RC, Perry CK, Shannon J, Ko LK, Wheeler SB, Odahowski CL, Farris PE, Eberth JM (2019) Rural-urban differences in financial burden among cancer survivors: an analysis of a nationally representative survey. Support Care Cancer 27(12):4779-4786

76. Zucca A, Boyes A, Newling G, Hall A, Girgis A (2011) Travelling all over the countryside: travel-related burden and financial difficulties reported by cancer patients in New South Wales and Victoria. Aust J Rural Health 19(6):298-305

77. Cipora E, Konieczny M, Karwat ID, Roczniak W, BabuskaRoczniak M (2018) Satisfaction with life among women with breast cancer-selected demographic and social factors. Ann Agric Environ Med 25(2):314-319

78. Corboy D, McLaren S, McDonald J (2011) Predictors of support service use by rural and regional men with cancer. Aust J Rural Health 19(4):185-190

79. McDowell ME, Occhipinti S, Ferguson M, Chambers SK (2011) Prospective predictors of psychosocial support service use after cancer. Psycho-Oncology 20(7):788-791

80. Bazzell JL, Spurlock A, McBride M (2015) Matching the unmet needs of cancer survivors to resources using a shared care model. J Cancer Educ 30(2):312-318

81. Glasser M, Nielsen K, Smith SN, Gray C (2013) Psychosocial needs of rural survivors of cancer and their partners. J Psychosoc Oncol 31(3):319-333

82. Riley-Clark A, Pieper BB (2014) Psychosocial needs of cancer patients living in the Adirondacks: a needs assessment. J N Y State Nurses Assoc 44(1):22-29

83. Coker AL, Luu HT, Bush HM (2018) Disparities in women's cancer-related quality of life by Southern Appalachian residence. Qual Life Res 27(5):1347-1356

84. Costrini NV (2011) Quality of life of rural Georgia colorectal cancer survivors. J Med Assoc Ga 100(4):26-29

85. Steenland K, Goodman M, Liff J, Diiorio C, Butler S, Roberts P (2011) Quality of life among men with prostate cancer in rural Georgia. Urology 77(4):927-933
86. Befort CA, Klemp J (2011) Sequelae of breast cancer and the influence of menopausal status at diagnosis among rural breast cancer survivors. J Women's Health (Larchmt) 20(9):1307-1313

87. Duggleby WD, Williams A, Holstlander L, Thomas R, Cooper D, Hallstrom LK, Ghosh S, O-Rourke H (2014) Hope of rural women caregivers of persons with advanced cancer: guilt, self-efficacy and mental health. Rural Remote Health 14:2561

88. Lashbrook M, Bernardes CM, Kirshbaum MN, Valery PC (2018) Physical functioning and psychological morbidity among regional and rural cancer survivors: a report from a regional cancer centre. Aust J Rural Health 26(3):211-219

89. Schlegel RJ, Manning MA, Molix LA, Talley AE, Bettencourt B (2012) Predictors of depressive symptoms among breast cancer patients during the first year post diagnosis. Psychol Health 27(3):277-293

90. Mandaliya H, Ansari Z, Evans T, Oldmeadow C, George M (2016) Psychosocial analysis of cancer survivors in rural Australia: focus on demographics, quality of life and financial domains. Asian Pac J Cancer Prev 17(5):2459-2464

91. Pisu M, Azuero A, Benz R, McNees P, Meneses K (2017) Out-ofpocket costs and burden among rural breast cancer survivors. Cancer Med 6(3):572-581

92. McNulty JA, Nail L (2015) Cancer survivorship in rural and urban adults: a descriptive and mixed methods study. J Rural Health 31(3):282-291

93. Hubbard G, Venning C, Walker A, Scanlon K, Kyle RG (2015) Supportive care needs of women with breast cancer in rural Scotland. Support Care Cancer 23(6):1523-1532

94. Martinez-Donate AP, Halverson J, Simon NJ, Strickland JS, Trentham-Dietz A, Smith PD, Linskens R, Wang X (2013) Identifying health literacy and health system navigation needs among rural cancer patients: findings from the Rural Oncology Literacy Enhancement Study (ROLES). J Cancer Educ 28(3): 573-581

95. Torres E, Dixon C, Richman AR (2016) Understanding the breast cancer experience of survivors: a qualitative study of African American women in rural eastern North Carolina. J Cancer Educ 31(1):198-206

96. Australian Institute of Health and Welfare (2019) Cancer in Australia 2019. AIHW. https://www.aihw.gov.au/reports/cancer/ cancer-in-australia-2019. Accessed 2 March 2020

97. Bettencourt BA, Talley AE, Molix L, Schlegel R, Westgate SJ (2008) Rural and urban breast cancer patients: health locus of control and psychological adjustment. Psycho-Oncol : Journal of the Psychological, Social and Behavioral Dimensions of Cancer 17(9):932-939

98. Bain NS, Campbell NC (2000) Treating patients with colorectal cancer in rural and urban areas: a qualitative study of the patients' perspective. Fam Pract 17(6):475-479. https://doi.org/10.1093/ fampra/17.6.475

99. Kroneman M, Verheij R, Tacken M, van der Zee J (2010) Urbanrural health differences: primary care data and self reported data render different results. Health Place 16(5):893-902. https://doi. org/10.1016/j.healthplace.2010.04.015

100. Australian Government (2019) Australian jobs 2019. Department of Jobs and Small Business. https://australianjobs.employment. gov.au/. Accessed 21 September 2020

Publisher's note Springer Nature remains neutral with regard to jurisdictional claims in published maps and institutional affiliations. 


\section{Affiliations}

Shannen R. van der Kruk ${ }^{1,2,3}$ (D) Phyllis Butow $^{4}$ (D) Ilse Mesters ${ }^{1}$ (D) Terry Boyle $^{3}$ (D) Ian $_{\text {Olver }}^{5}$ (D) Kate White $^{6}$ (D) Sabe Sabesan $^{7}$ (D) $\cdot$ Rob Zielinski $^{8,9}$ (D) Bryan A. Chan ${ }^{10}$ (D) Kristiaan Spronk $^{2,11}$ (D) Peter Grimison $^{12}$ (D)

Craig Underhill ${ }^{13}$ (D) Laura Kirsten ${ }^{14} \cdot$ Kate M. Gunn ${ }^{2,11}$ (D) on behalf of the Clinical Oncological Society of Australia

1 Department of Epidemiology, Maastricht University, Maastricht, The Netherlands

2 Cancer Research Institute, University of South Australia, Adelaide, SA, Australia

3 Australian Centre for Precision Health, School of Health Sciences, University of South Australia, Adelaide, SA, Australia

4 Centre for Medical Psychology and Evidence-Based DecisionMaking, The University of Sydney, Sydney, NSW, Australia

5 Faculty of Health and Medical Sciences, University of Adelaide, Adelaide, SA, Australia

6 Faculty of Medicine and Health, The University of Sydney, Sydney, NSW, Australia

7 College of Medicine and Dentistry (CMD), James Cook University, QLD, Townsville, Australia
8 Central West Cancer Care Centre, Orange Base Hospital, Orange, NSW, Australia

9 Western Sydney University, Sydney, NSW, Australia

10 School of Medicine, Griffith University, Brisbane QLD, Australia

11 Department of Rural Health, Allied Health and Human Performance, University of South Australia, Adelaide, SA, Australia

12 Department of Medical Oncology, Chris O’Brien Lifehouse, Sydney, NSW, Australia

13 Border Medical Oncology, Albury, Australia

14 Nepean Cancer Care Centre, Penrith, NSW, Australia 